\title{
IdeAs
}

Idées d'Amériques

$15 \mid 2020$

Eau et gestion de l'eau dans les Amériques

\section{Vulnérabilité, risques et conflits liés à l'eau : la zone de protection environnementale de la plaine inondable du Tietê}

Vulnerabilidade, riscos e conflitos relacionados à água: a APA da várzea do rio Tietê

Vulnerability, risks and conflicts related to water: the Tietê river floodplain APA

Neli Aparecida de Mello-Théry, Hervé Théry, Danilo Pereira Sato et Heloisa de Camargo Tozato

\section{(2) OpenEdition}

Édition électronique

URL : http://journals.openedition.org/ideas/8197

DOI : $10.4000 /$ ideas.8197

ISSN : $1950-5701$

Éditeur

Institut des Amériques

Référence électronique

Neli Aparecida de Mello-Théry, Hervé Théry, Danilo Pereira Sato et Heloisa de Camargo Tozato, «Vulnérabilité, risques et conflits liés à l'eau : la zone de protection environnementale de la plaine inondable du Tietê », IdeAs [En ligne], 15 | 2020, mis en ligne le 01 mars 2020, consulté le 25 mars 2020. URL : http://journals.openedition.org/ideas/8197 ; DOI : https://doi.org/10.4000/ideas.8197

Ce document a été généré automatiquement le 25 mars 2020

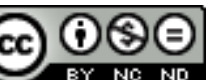

IdeAs - Idées d'Amériques est mis à disposition selon les termes de la licence Creative Commons Attribution - Pas d'Utilisation Commerciale - Pas de Modification 4.0 International. 


\title{
Vulnérabilité, risques et conflits liés à l'eau : la zone de protection environnementale de la plaine inondable du Tietê
}

\author{
Vulnerabilidade, riscos e conflitos relacionados à água: a APA da várzea do rio \\ Tietê \\ Vulnerability, risks and conflicts related to water: the Tietê river floodplain APA \\ Neli Aparecida de Mello-Théry, Hervé Théry, Danilo Pereira Sato et Heloisa \\ de Camargo Tozato
}

\section{Introduction}

1 Carlos Nobre, climatologue et membre du GIEC (récompensé du prix Nobel de la Paix en 2007), longtemps chercheur à l'Institut National d'Études Spatiales brésilien (Instituto Nacional de Pesquisas Espaciais- Inpe) a l'habitude de commencer ses conférences sur le climat de la ville de São Paulo en disant que celle-ci est un véritable laboratoire des effets du changement climatique sur la vulnérabilité et les risques liés à l'eau. En effet, comme il l'indique, les températures moyennes y ont déjà augmenté de 2 à 3 degrés, les pluies y sont devenues plus courtes et plus violentes, la garoa (crachin) qui était caractéristique de son climat a disparu et a été remplacée par des orages courts et intenses qui causent des inondations catastrophiques dans la vallée du Tietê, le cours d'eau qui traverse la ville.

C'est pourquoi il est particulièrement intéressant d'analyser la situation de l'aire de protection de la plaine inondable du Tietê (Area de Proteção Ambiental das Várzeas do Rio Tietê-APA-VRT). Elle se situe au cœur de la principale métropole brésilienne, São Paulo, qui compte près de vingt millions d'habitants et produit près de $20 \%$ du PIB du Brésil. Elle constitue un des principaux espaces verts de sa région orientale (la Zona Leste, 4,5 
millions d'habitants), qui en manque le plus, et a un effet sensible sur le climat urbain en créant un "îlot de fraicheur » qui contrebalance en partie les effets de l'« îlot de chaleur » urbain (Lombardo M. 1985) ${ }^{1}$. Elle contribue, en retenant une partie des eaux venues de l'amont, à régulariser les crues qui atteignent régulièrement la ville de São Paulo. Pour toutes ces raisons a été créée une zone de protection de l'environnement de la plaine inondable du Tietê, l'APA-VRT, qui devait à la fois protéger ce milieu original et fragile et en assurer l'intégration harmonieuse à la ville, à laquelle elle devrait rendre de précieux services.

Cela n'a malheureusement pas été tout à fait le cas et les pressions de tous ordres démographiques, immobilières, agricoles et industrielles - ont grandement compromis le fonctionnement des várzeas et l'analyse qui suit vise, pour contribuer au débat sur la vulnérabilité et les risques liés à l'eau en contexte de changement climatique, à montrer toute la complexité de la situation actuelle, les enchaînements de causes et effets dont elle résulte et les responsabilités des différents acteurs dont les intérêts divergents s'affrontent autour de ces plaines inondables.

4 Le texte qui suit s'ouvre par une présentation des vulnérabilités et des risques de ces plaines inondables dans l'APA-VRT, puis propose une analyse de l'utilisation des terres et de ses changements récents (urbanisation pour les classes moyennes, aisées et populaires, production horticole, industries). Suit une étude des agents et des processus de transformation de l'APA-VRT. Nous analyserons ensuite les politiques et projets dans la zone de protection environnementale de la zone inondable du Tietê et les enchevêtrements qui en limitent l'efficacité.

\section{Le Tietê, au cœur de São Paulo}

5 Le Tietê est étroitement associé à la ville et à l'Etat de São Paulo (Théry H., 2016). Il prend sa source dans la commune de Salesópolis (à 820 mètres d'altitude, dans la Serra do Mar, la chaîne montagneuse qui marque le rebord du plateau central), à environ 120 kilomètres en amont de la ville de São Paulo. Il s'étend sur près de $1150 \mathrm{~km}$ et se jette dans le Paraná (dans le lac du barrage de Jupiá), après avoir traversé la ville et l'Etat de São Paulo dans le sens sud-est/nord-ouest (figure 1). Son bassin couvre plus de 150000 $\mathrm{km}^{2}$ et ses eaux sont utilisées tant pour les besoins des populations riveraines et pour l'irrigation que pour la production d'énergie et le transport. La multiplicité des occupations illégales et l'usage désordonné des sols sont la cause d'une intense pollution qui commence dès les quarante premiers kilomètres en aval de la source. 


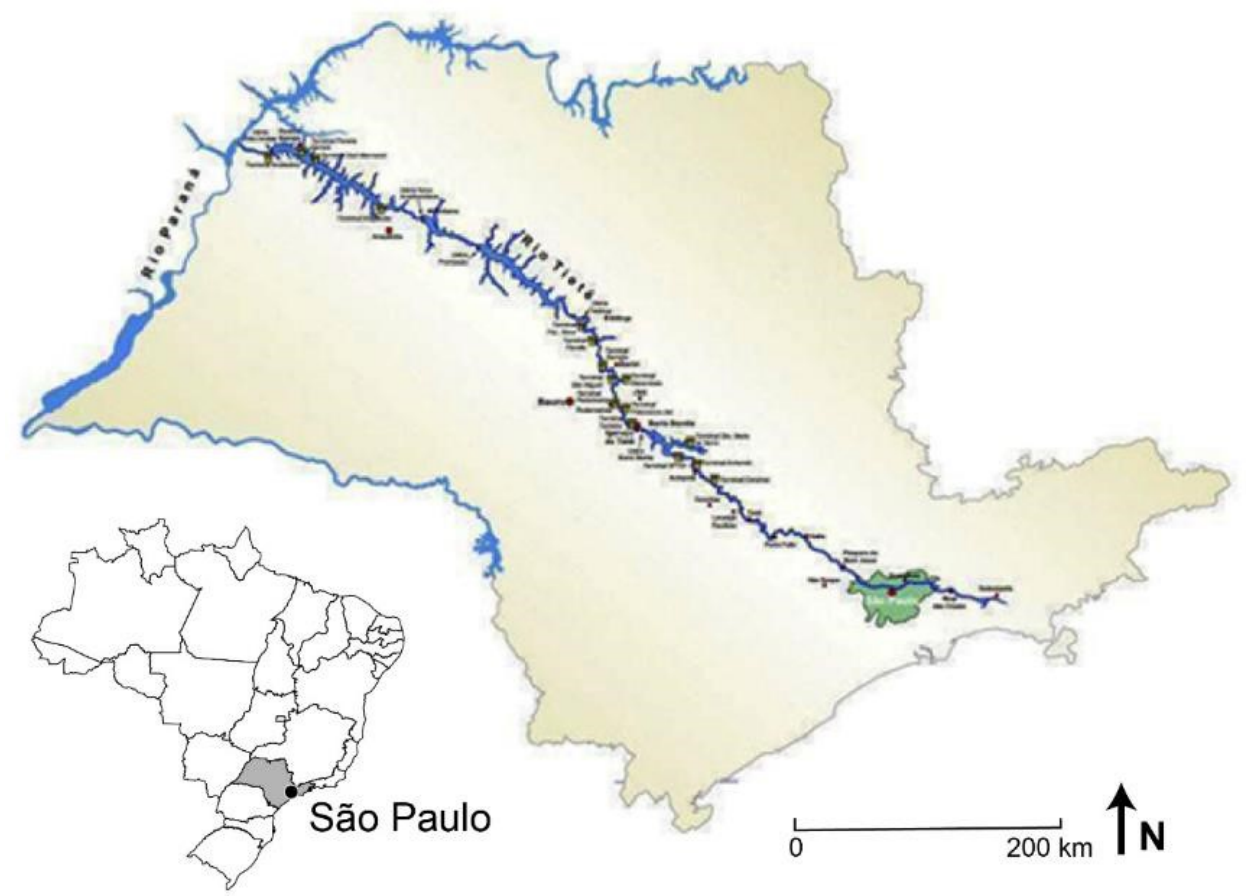

Source : Neli Aparecida de Mello-Théry, Hervé Théry, Danilo Pereira Sato, Heloisa de Camargo Tozato

Les plaines d'inondation du Tietê (APA-VRT) ont une faible superficie, néanmoins le fait d'être situées dans la région métropolitaine de São Paulo leur confère une importance toute particulière. Elles sont l'objet de pressions de l'expansion urbaine, de la mise en place d'infrastructures et de différentes activités économiques, dont certaines sont anciennes, comme l'extraction de sable. S'y pose également la question du déversement des eaux usées, de la construction des voies périphériques, de l'installation des trains urbains et de la présence de l'agriculture sur les plaines d'inondation.

7 La zone de protection de l'environnement des plaines inondables du Tietê (Área de proteção ambiental das várzeas do rio Tietê / APA-VRT) concerne douze communes (figure 2)2 de la région métropolitaine de São Paulo. Fondée en 1987 (loi de l'État de São Paulo $n^{\circ} 5598 / 87$ ) pour protéger les plaines inondables du Tietê, elle s'étend sur 7400 hectares. La loi y a interdit les lotissements et établit des zones de vie sylvestre. Elle est définie comme une unité de conservation environnementale (par le Système national d'unités de conservation, SNUC), et se superpose à la zone de préservation permanente (APP, Área de proteção permanente) des plaines inondables.

L'APA est interrompue dans la partie centrale de São Paulo, ce qui nuit évidemment à son fonctionnement mais le cours fluvial y est si transformé que l'inclure dans une aire de protection environnementale n'aurait plus eu aucun sens: la voie sur berge dite «marginal do Tietê » compte par endroits jusqu'à onze voies en bordure du cours d'eau, qui a été rectifié, canalisé et curé à de multiples reprises. 


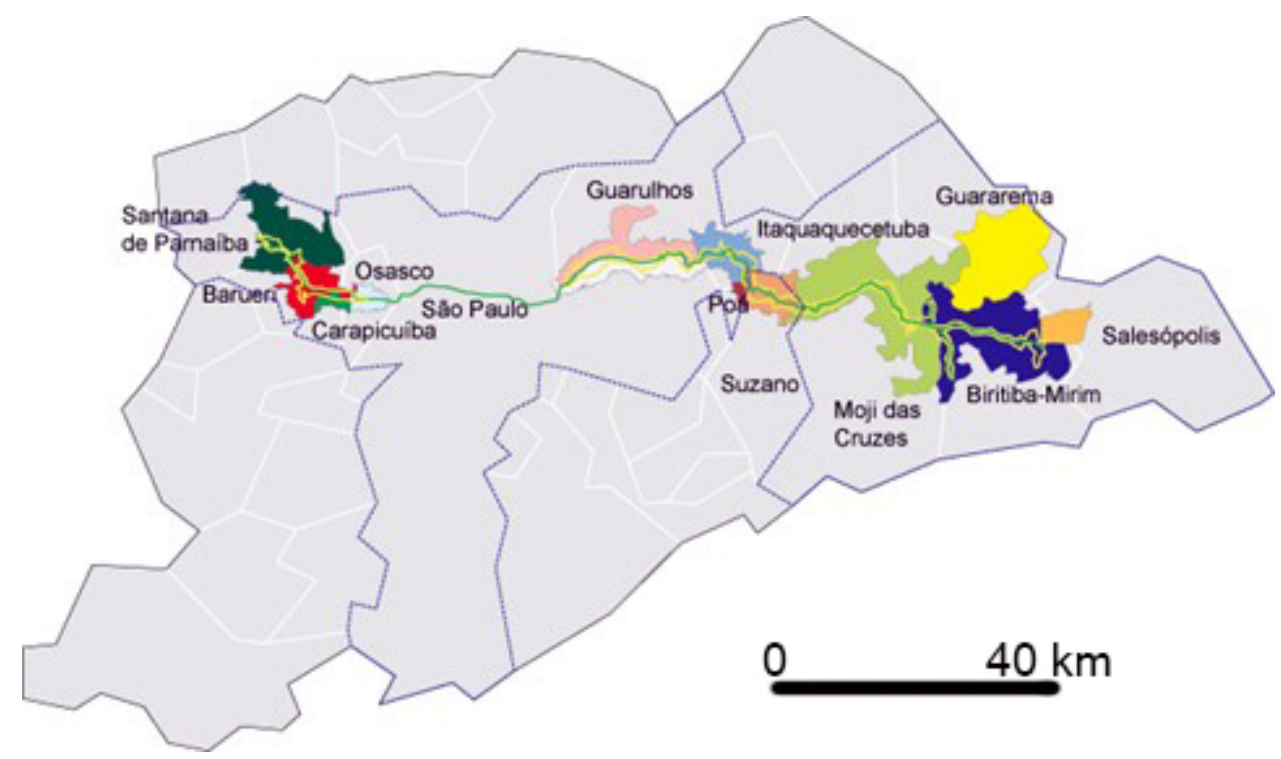

Source : Neli Aparecida de Mello-Théry, Hervé Théry, Danilo Pereira Sato, Heloisa de Camargo Tozato

Une étude détaillée de la zone de protection de l'environnement des plaines inondables du Tietê et de son entourage immédiat a été menée dans le cadre de la préparation du plan de gestion de l'APA-VRT ${ }^{3}$. Nous avons analysé, au-delà des limites de l'APA, une zone-tampon d'un kilomètre et, pour les données socio-économiques, l'ensemble des secteurs censitaires dans laquelle elle s'inscrit (figure 3).

Figure 3 Le tracé de l'APA-VRT et les secteurs censitaires analysés

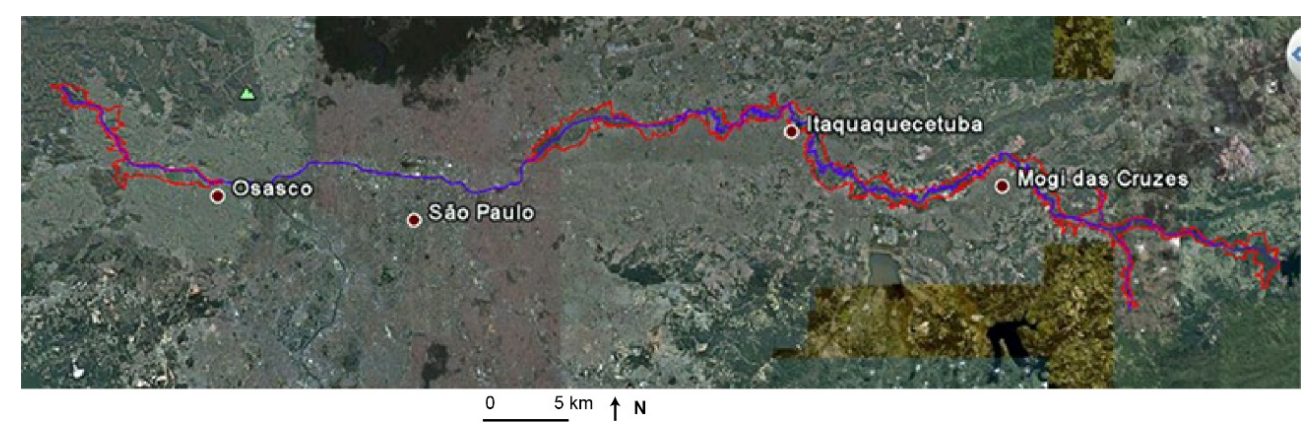

Source : Neli Aparecida de Mello-Théry, Hervé Théry, Danilo Pereira Sato, Heloisa de Camargo Tozato

10 L'étude a été fondée, pour la morphologie fluviale, sur la méthodologie des niveaux de perturbation morphologique de la plaine fluviale du Tietê (Rodrigues C., $2015: 335$ ), prenant en compte les zones de méandres d'origine, les superficies originales de plaines et de terrasses et les fragments de la forêt marécageuse. Pour l'analyse des politiques publiques nous avons pris en compte le référentiel législatif, les normes liées aux zones de protection de l'environnement et aux zones de protection permanente, de façon à repérer la superposition de politiques et d'actions publiques étatiques et municipales. Des campagnes de terrain et des interviews avec des acteurs-clés des autorités locales et des associations d'habitants (dont leur inventaire complet) ont été réalisés. Quelques-uns des points de ce travail sont repris ci-dessous, alors que d'autres ont été laissés de côté, comme les analyses climatiques et les inventaires de faune et de flore. 


\section{Les plaines inondables, I'APA-VRT, vulnérabilités et risques}

11 Rappelons d'abord les principales définitions de "vulnérabilité » et "risques ». On parle de vulnérabilité lorsque, face à une perturbation, la réponse de l'environnement dépend de ses caractéristiques locales, naturelles et humaines. C'est-à-dire que " chaque fraction du territoire a une condition intrinsèque qui, en interaction avec le type d'ampleur de l'événement que nous provoquons, a pour effet une quantité d'effets négatifs " (Santos, R. 2007 : 20). Pour le GIEC (IPCC, 2014: 6), la vulnérabilité est la prédisposition à être soumis à des effets néfastes et peut se produire en raison de plusieurs facteurs, sociaux ou physiques. Deux aspects sont intrinsèques à la vulnérabilité : sa persistance est liée à l'équilibre de l'environnement local et sa résilience liée au retour à son état d'équilibre. La vulnérabilité compte généralement plusieurs classes ou degrés et peut être déterminée comme élevée, moyenne, faible.

Le risque environnemental a été à l'origine systématisé par Talbot Page en 1978, lorsqu'il a clairement distingué la vision traditionnelle de la pollution du concept de risque, qui est lié à l'incertitude et à l'ignorance des véritables dimensions du problème environnemental. Il peut être défini dans les limites entre deux conceptions radicalement distinctes de l'évaluation des ressources naturelles, de rentabilité et de durabilité. Bien que la notion de risque ait toujours été appliquée dans les évaluations des investissements et prenne en compte des catastrophes naturelles à différentes échelles et périodes de temps, elle exprime désormais également la dimension sociale des événements catastrophiques et la perception individuelle de leurs effets (Fortunato I. et J. Fortunato Neto, 2012).

13 On peut distinguer, selon Egler C. (1996) trois catégories de base : risque naturel, social et technologique :

14 a) le risque naturel est associé au comportement dynamique des systèmes naturels et lié au degré d'instabilité exprimé dans leur vulnérabilité aux événements critiques à court ou long terme. On y range, par exemple, les inondations, les glissements de terrain et l'accélération des processus érosifs, dans le cas de cette analyse, liés au Tietê lui-même

15 b) le risque technologique est lié à des évènements mettant des vies en danger, à court, moyen et long terme, et résultant de décisions d'investissement dans la structure de production. Elle implique une évaluation à la fois de la probabilité d'explosions, de fuites ou de déversements de produits toxiques, de la contamination à long terme des systèmes naturels par le rejet et l'élimination des déchets du processus de production.

c) le risque social résulte de l'insuffisance de développement humain complet, qui contribue à la dégradation des conditions de vie. Il se manifeste dans les conditions d'habitabilité, par la fragilité des maisons elles-mêmes, dans l'accès aux services de base (traitement de l'eau, collecte des ordures). L'occupation illégale de zones protégées par la législation (fonds de vallée et de plaine inondable) est un exemple classique d'aggravation du risque social identifié dans l'APA-VRT. À long terme, elle affecte la formation technique de la population locale, l'emploi et les revenus et, par conséquent, le plein développement humain durable. 
17 La complexité actuelle de la dynamique des risques exige la création de nouvelles catégories de risques et a suscité de nombreuses nouvelles approches, cependant, comme nous nous intéressons au risque comme critère de gestion du territoire, nous avons choisi de nous appuyer sur la définition d'Egler C. (1996) et de mettre en évidence les effets de la forte croissance démographique et de l'urbanisation des várzeas dans la région métropolitaine de São Paulo. Nous l'avons associée à la définition de la vulnérabilité de Santos R. (2007), celle qui soumet la population locale aux effets néfastes des différents facteurs, mettant en évidence les conditions de santé et de logement médiocres, les inondations fréquentes de la várzea, par exemple.

\section{L'APA-VRT dans le système brésilien de protection de l'environnement}

Pour mieux saisir la situation de l'APA-VRT, il convient de préciser qu'au Brésil, les plaines inondables sont des zones de préservation permanente (APP), un concept établi par le Code Forestier de 1965 (loi fédérale $n^{\circ} 4771$ ) pour «la conservation et la préservation de zones proches de phénomènes naturels qui ont besoin de protection pour leur permanence et leur fonction environnementale ».

19 Protéger ces espaces est une nécessité parce que dans le milieu rural brésilien, beaucoup ont été utilisés pour l'agriculture (voire les monocultures), avec pour conséquence les impacts les plus divers sur l'environnement: ensablement de cours d'eau, installation de processus érosifs, déforestation de forêts ciliaires ${ }^{4}$ empêchant le flux génique de la flore et de la faune et causant un appauvrissement des sols, en particulier de ceux dont la fertilité naturelle est faible.

20 En ville, la loi $n^{\circ} 7803 / 89$ a imposé des limites et établi des définitions pour les zones de préservation permanente. La loi $n^{\circ} 6766 / 79$ (et ses modifications ultérieures) ont encadré les projets de lotissement du sol dans des aires d'expansion urbaine définies selon les lois municipales. Parmi les conditions urbanistiques, elle a déterminé des zones non aedificandi (non constructibles) le long de cours d'eaux courantes et dormantes, avec une obligation de réserve d'au moins quinze mètres sur chaque berge. Cependant, les principes de ces dispositifs n'admettent pas l'utilisation en zone de préservation permanente et les pouvoirs publics peuvent imposer plus d'exigences car ils ont la prérogative légale de définir ce qu'est l'espace urbain et son expansion : ils peuvent les accroître, mais jamais les revoir à la baisse.

21 La controverse sur les zones de préservation permanente associées à des cours d'eau et, par extension, aux autres milieux naturels non protégés, vient surtout des dispositifs de lois fédérales, décrets, résolutions, arrêtés, etc. qui régulent la délivrance de permis environnementaux à des projets de développement aux interventions que peuvent réaliser les états fédérés et les municipalités.

Par ailleurs, ces lois de développement urbain peuvent être liées au Système national des unités de conservation (SNUC). Dans les unités de conservation d'usage durable, celles qui présentent le moins de restrictions d'utilisation sont les zones de préservation environnementale (APA); elles doivent seulement indiquer les taux et modalités d'occupation dans leur plan de gestion. Elles peuvent donc être vues comme des espaces pour la planification intégrant la conservation et des utilisations urbaines ou rurales. 

" rectification » du Tietê et l'occupation de ses terrasses alluviales. Même si des plans de rectification étaient prévus depuis 1894, l'aménagement du Tietê n'a commencé dans la commune de São Paulo qu'avec le «Plan des Avenues » du gouvernement Pires do Rio (1926-1930) et s'est poursuivi jusque dans les années 1960, avec le développement des transports routiers et du marché immobilier. Ce dernier met en avant des arguments d'assainissement et de lutte contre les crues pour attribuer de nouvelles utilités aux zones désoccupées des plaines d'inondation (Gouveia I. C., 2016).

27 À titre d'exemple, la figure 4 est un extrait de l'une des trois cartes réalisées pour l'étude, elle ne porte que sur l'extrémité occidentale du secteur principal (périmètre 2). Elle montre la vulnérabilité à l'inondation selon la classification du plan de gestion (Fundação Florestal, 2013) : basse, moyenne, forte et très forte. La forte augmentation de la vulnérabilité serait due à l'occupation des várzeas par des zones d'habitat illégal ${ }^{5}$. Nous y reviendrons dans la troisième partie. 
Figure 4 Répartition de la vulnérabilité aux inondations dans le périmètre 2 de la zone de protection environnementale des plaines inondables du Tietê (APA-VRT)

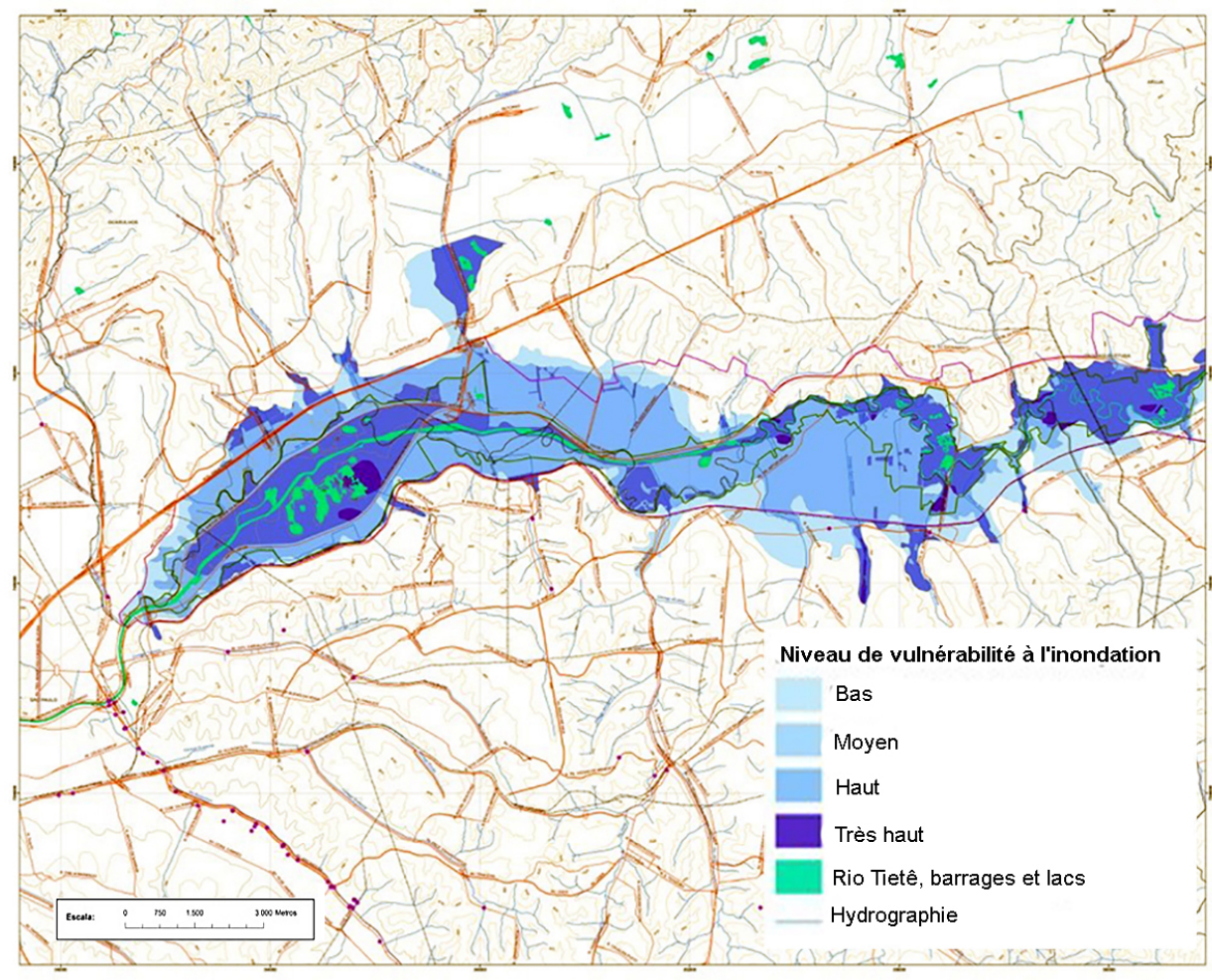

Source : Diagnostic de l'environnement physique, Plan de gestion de l'APA-VRT (Fundação Florestal 2013)

\section{L'utilisation des terres et les occupations dans des zones vulnérables}

Toutes les régions métropolitaines brésiliennes possèdent encore des zones inoccupées et disponibles pour l'urbanisation, issues de l'activité rurale, de l'exploitation minière ou abandonnées parce que jugées économiquement sans intérêt. Ces zones sont intéressantes pour le secteur de l'immobilier parce qu'elles sont proches du centre de la métropole, donc de ses services et de ses infrastructures. La demande augmente continuellement pour des lotissements et des copropriétés résidentielles (condomínios ${ }^{\natural}$ ) de luxe, mais aussi des constructions institutionnelles. Le prix $\mathrm{du}^{2} \mathrm{~m}^{2}$ est encore attractif, on y trouve des équipements de loisirs et la sécurité est y assurée, ce sont donc des espaces prioritaires pour un segment de la population qui recherche confort, sécurité et déplacements compatibles avec ses intérêts. Par ailleurs les occupations irrégulières y ont augmenté, dans des zones normalement inconstructibles, ce qui renforce encore la croissance horizontale urbaine.

Dans le cas des várzeas de la région métropolitaine de São Paulo, les aires disponibles sont situées à la limite des zones de préservation permanente, voire à l'intérieur. Dans l'APA-VRT, nombre de ces zones sont des forêts résiduelles en bon état de conservation ${ }^{7}$, avec même la présence d'une faune résiduelle.

Ces zones rémanentes fournissent des services écosystémiques écologiques, sociaux, esthétiques et économiques. Par exemple, les forêts ont un rôle dans la réduction de la 
température, l'augmentation des précipitations, l'interception des pluies, l'infiltration de l'eau dans le sol, l'augmentation de l'humidité atmosphérique, la réduction de polluants, l'interception du rayonnement solaire, la réduction de la vitesse du vent, l'atténuation des bruits, l'amélioration de la qualité de l'air, l'équilibre mental et psychologique de la population (Tryväinen L. et al., 2005).

En plus des forêts résiduelles, certaines zones d'expansion urbaine à l'intérieur de l'APA-VRT possèdent encore les caractéristiques du milieu rural. Cependant, elles tendent à disparaître avec le rapprochement des limites de la ville et le projet urbain. La conversion du sol a lieu par l'intermédiaire de projets urbains présentés à la mairie qui, en retour, fournit les directrices urbanistiques. Il y a donc ici possibilité de conflits étant donné que l'instance de décision de la zone de protection environnementale relève d'un agent étatique et la conversion du sol de la municipalité.

Sur le plan méthodologique, cette étude s'est appuyée sur des images satellites de ces zones pour identifier différentes utilisations et occupations et ainsi observer le degré de préservation, d'altération et d'effet de bord de la végétation dans l'APA-VRT et dans son entourage immédiat. La sélection des lieux a été basée sur :

I. Une typologie des formes principales d'utilisation et d'occupation du sol dans la zone de protection environnementale et dans le buffer d'un kilomètre au-delà des limites de l'APA choisi comme zone d'étude: urbanisation de la plaine d'inondation et de faible revenu, copropriétés des classes moyennes et des classes aisées, industrialisation de la plaine d'inondation, production horticole et élevage de petits animaux. L'objectif était de voir et de photographier sur le terrain (en spécifiant les coordonnées géographiques) les principaux types détectés dans le traitement des images satellites;

II. Des exemples caractéristiques de transformation de l'utilisation et de l'occupation des terres en comparant les années 2002, 2007 (cartographie Emplasa ${ }^{8}$ ) et 2011 (travail de terrain). L'objectif était de vérifier la réalité et l'extension de la transformation, mais aussi d'observer ce qui s'est passé dans ces endroits.

En outre, pour chaque lieu d'étude a été prise une série de photographies représentatives $d u$ paysage dominant géoréférencée de deux manières: selon la définition classique de sa longitude et de sa latitude (mesurée par un GPS), et sa localisation à partir de ces coordonnées sur une carte Google Earth (image satellite, rues/routes avec nomenclature); et dans la plupart des cas, des photos et/ou des images Google Earth complémentaires (Théry H., 2011).

\section{Urbanisation des plaines d'inondation}

L'avancée de l'urbanisation dans la zone de protection environnementale est un des phénomènes les plus inquiétants de l'évolution de la région. Les figures 5 et 6 offrent une vision du front d'urbanisation qui va jusqu'au bord de la rivière, une situation qui augmente évidemment les risques de pollution hydrique et/ou les inondations. 
Figure 5 Urbanisation des plaines d'inondation dans I'APA-VRT

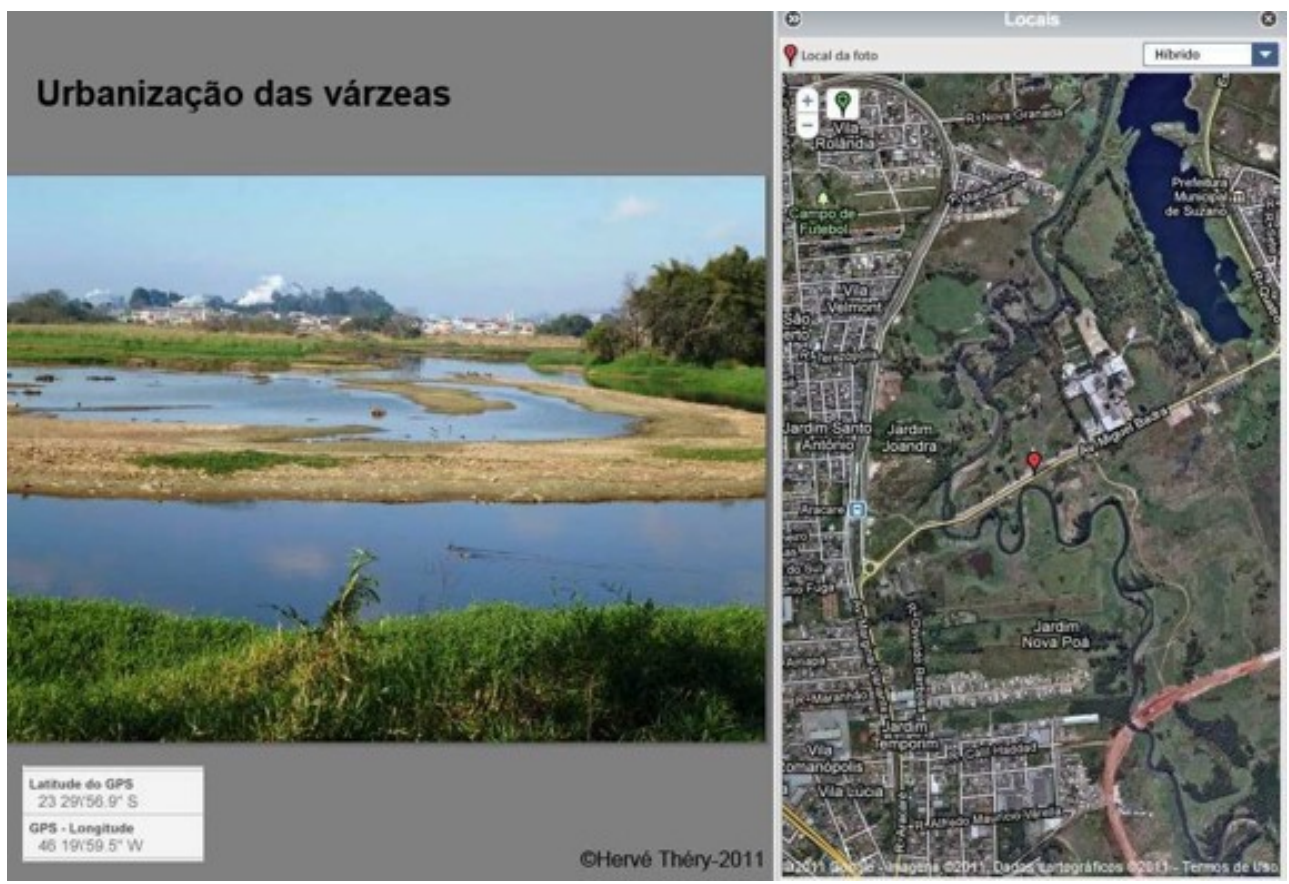

Figure 6 Urbanisation des várzeas dans l'APA-VRT (détail)

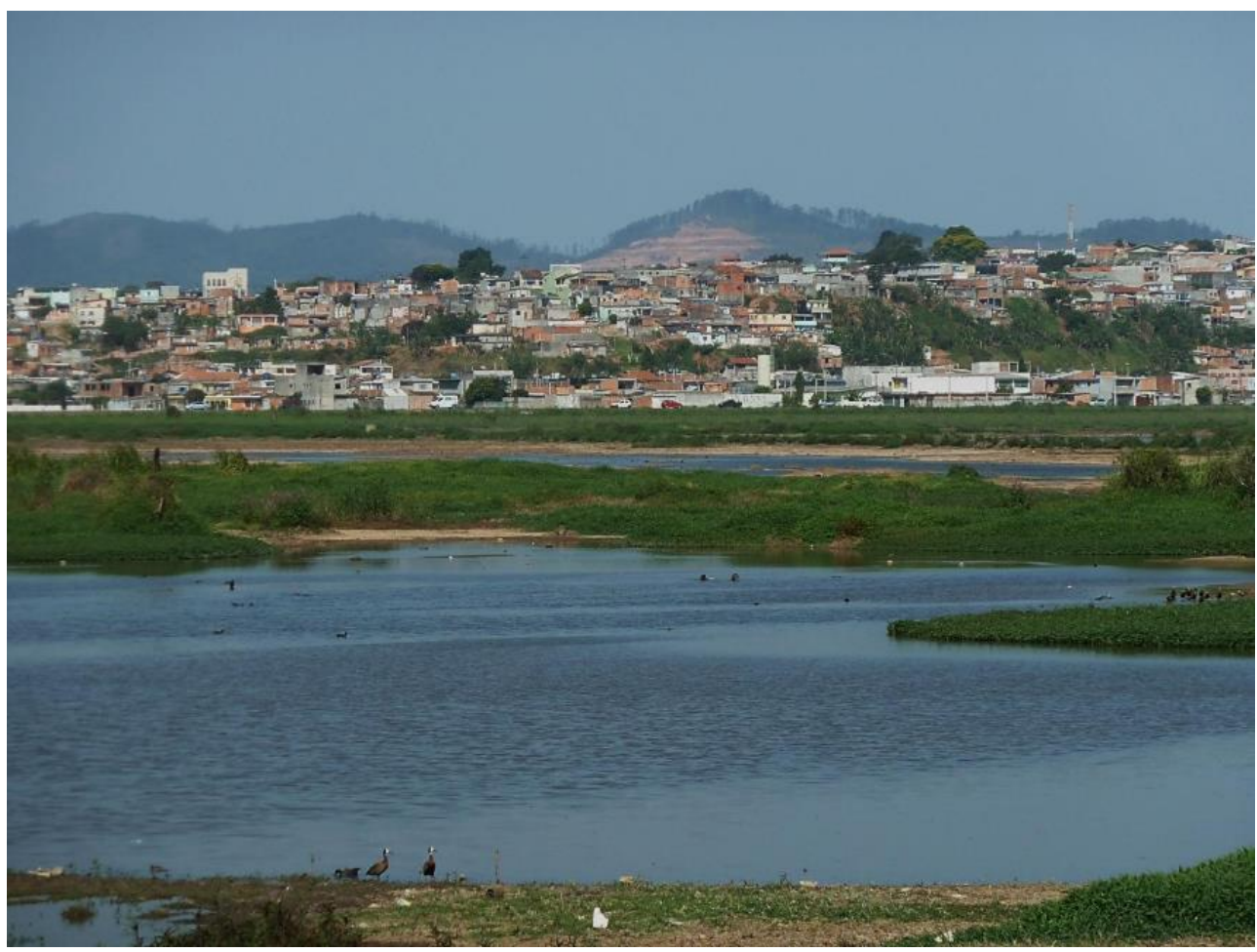

Source : Hervé Théry

35 Il faut toutefois distinguer plusieurs types d'urbanisation des várzeas, selon que cette occupation est menée par des lotissements destinés aux classes moyennes, aux classes aisées ou aux classes populaires. 


\section{Lotissements pour classes moyennes}

36 totalement occupée par la végétation native par un espace résidentiel, avec des rues et des parcelles où sont construites des maisons unifamiliales (figures 7,8 et 9). Sur la figure 7 la limite du côté de la plaine d'inondation (haut de l'image verticale) est très sinueuse et ne correspond à aucune déclivité ou autre limite naturelle.

Figure 7 Copropriété pour classe moyenne dans l'APA-VRT

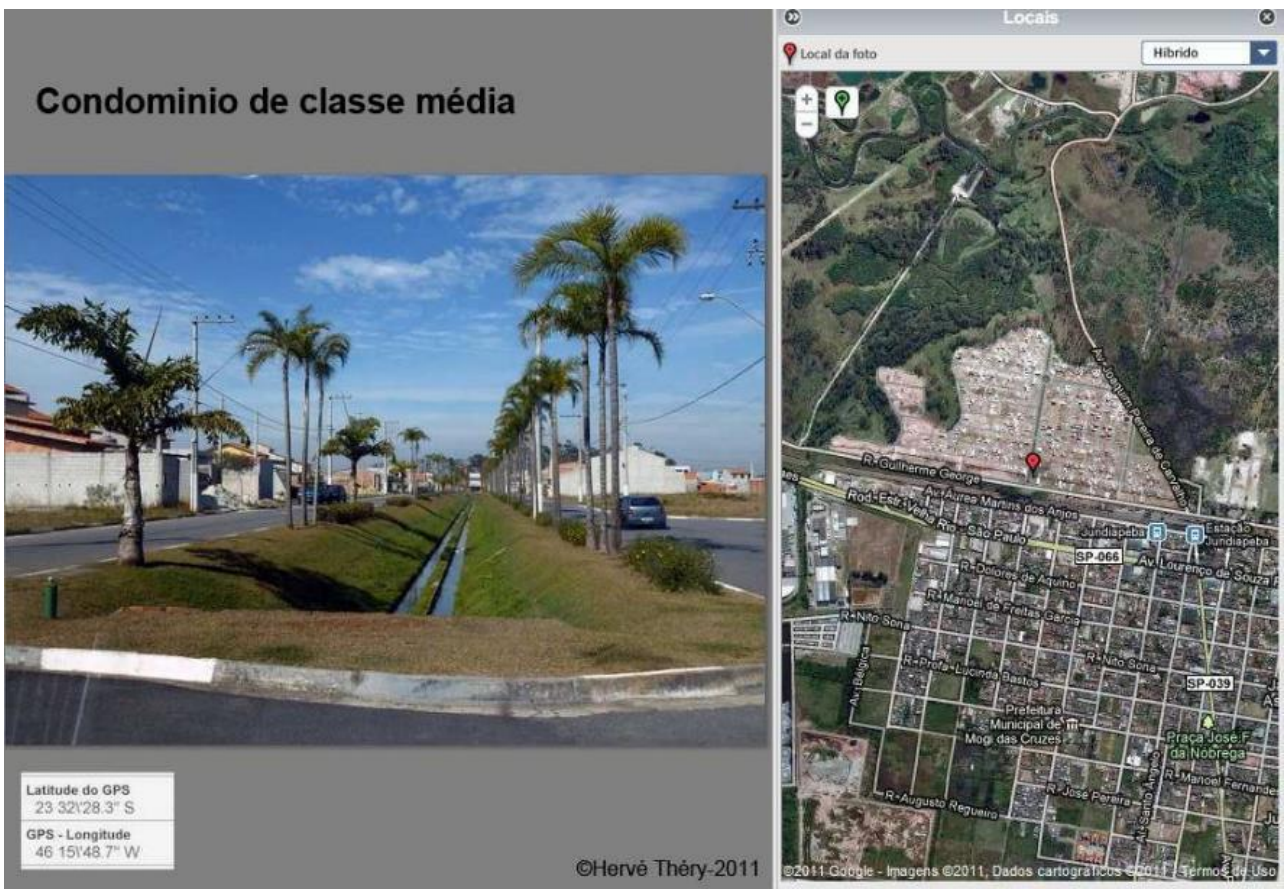
accessible uniquement par une entrée gardée 24 heures sur 24 (figure 8).

Figure 8 L'entrée du condomínio

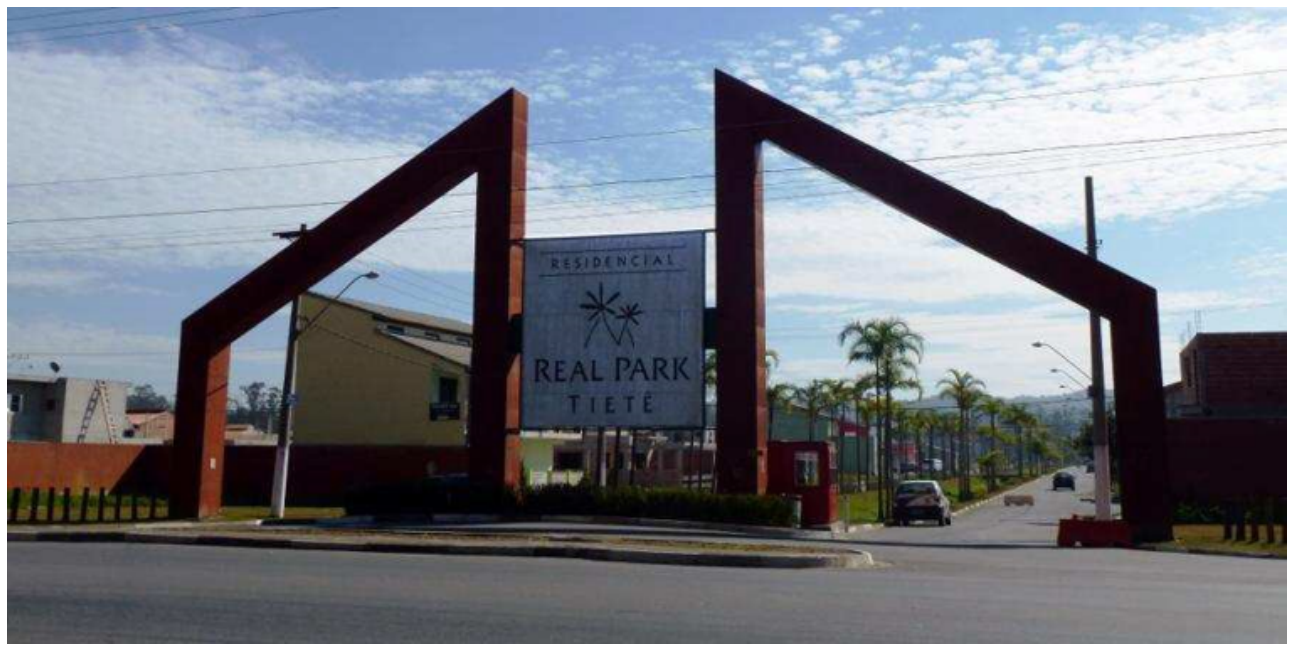

Source : Hervé Théry 
Figure 9 La clôture séparant le condomínio de l'APA-VRT

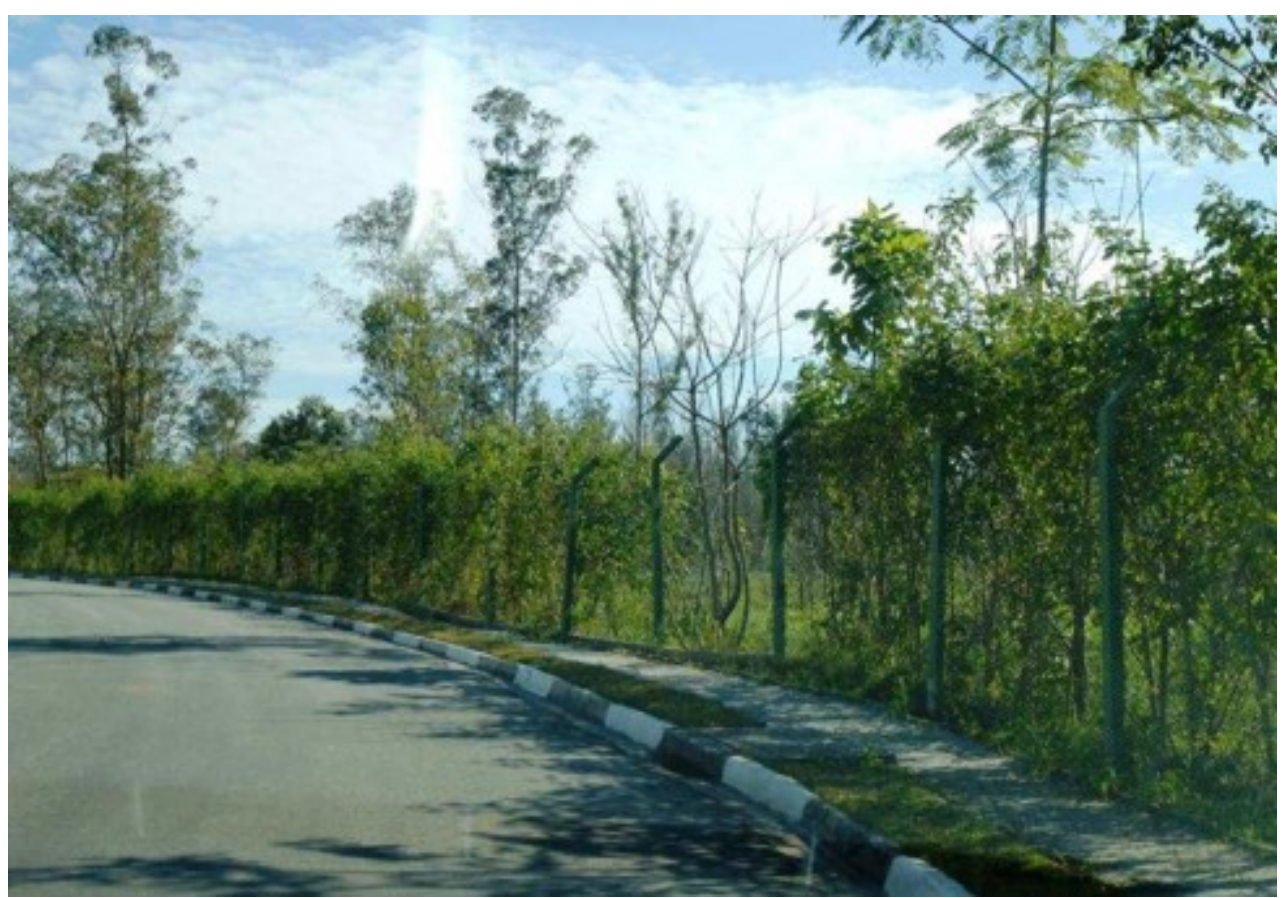

Source : Hervé Théry

Matérialisée par un grillage et une haie, la clôture du lotissement du côté de la rivière suit rigoureusement la limite de la zone de protection environnementale, indiquant par-là un bon niveau d'information des entrepreneurs et un - certain - respect de la législation environnementale.

\section{Lotissements pour classes aisées}

Une autre forte tendance observée dans la transformation de l'utilisation et de l'occupation du sol dans la zone de protection de l'environnement de la plaine d'inondation du Tietê et dans son entourage est la croissance d'espaces résidentiels fermés de haut standing (Figures 10 et 11), les condomínios de luxo.

Rechercher des aires dotées d'un milieu naturel agréable pour en faire un argument de vente peut représenter un sérieux risque environnemental. Le cas choisi en est un exemple, comme le montre la séquence d'images de Google Earth : une copropriété de haut standing installé dans une clairière créée dans une parcelle de forêt par un incendie: les promoteurs ont eu l'autorisation de la lotir en échange de la transformation du reste de la forêt en parc public, séparé du lotissement par des grilles. 
Figure 10 Lotissements pour classes aisées dans l'APA-VRT

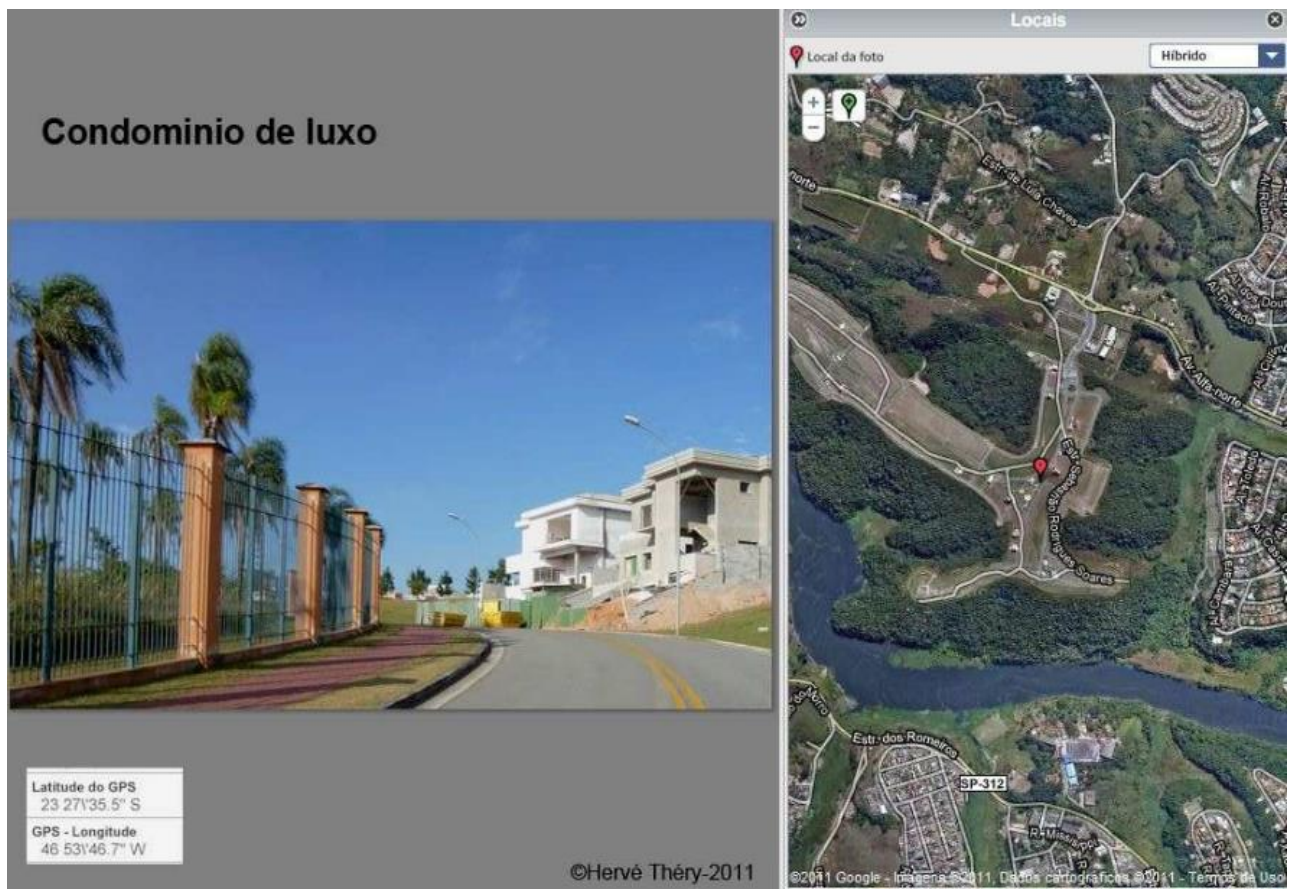

41 Le lotissement a été un succès, comme en témoigne la figure 11 : malgré un prix élevé 9 presque toutes ses parcelles ont été occupées

Figure 11 Évolution du lotissement 2002-2019

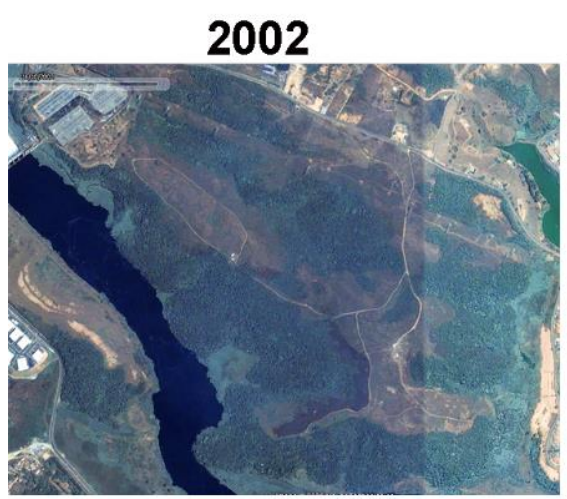

2015

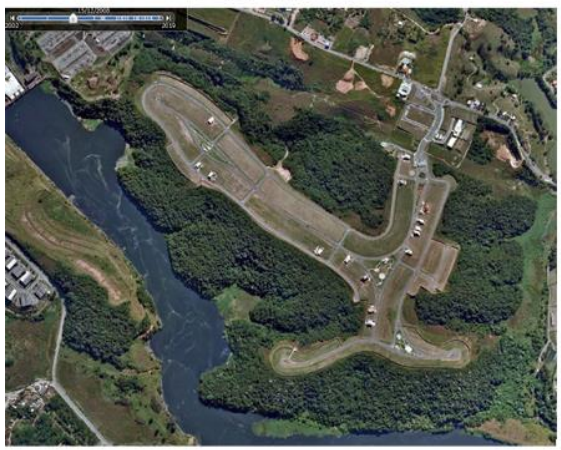

Source : Hervé Théry
2005

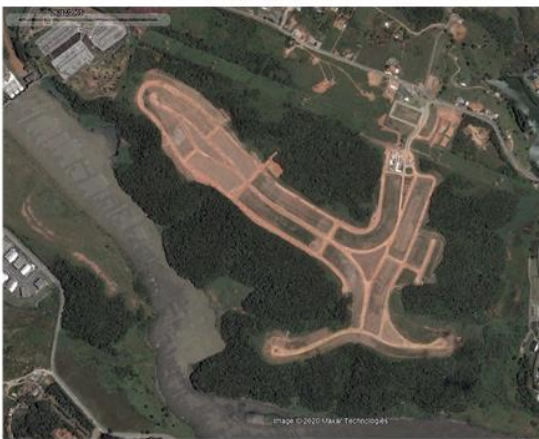

2019

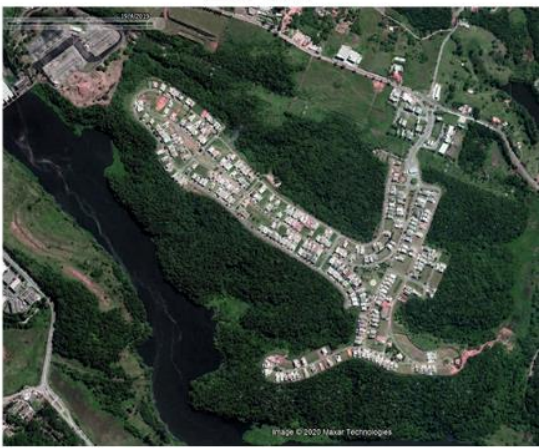




\section{Lotissements pour classes populaires}

Figure 12 Urbanisation pour classes populaires dans la zone de protection environnementale des plaines d'inondation du Tietê (APA-VRT)

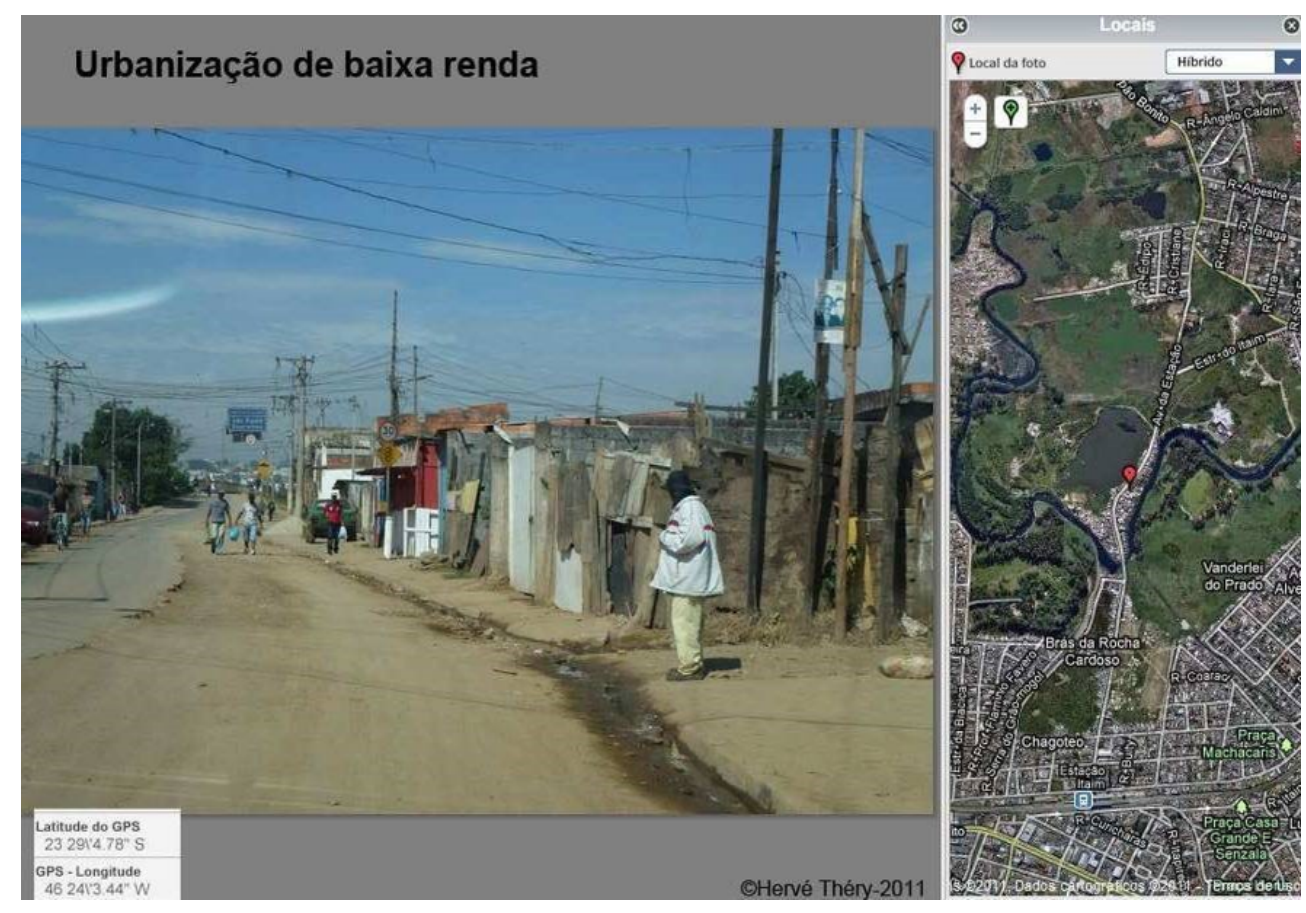

42 L'urbanisation désordonnée des zones inondables, particulièrement occupée ? par des populations à faibles revenus, est une des préoccupations majeures dans la région. Ces populations pauvres sont de loin les plus vulnérables. L'occupation des plaines inondables par des habitations précaires n'expose pas seulement la population qui y vit: le processus d'imperméabilisation du sol augmente les risques et la possibilité d'inondation. L'exemple le plus clair en est le quartier Jardim Romano et ses alentours où les figures 12 et 13 ont été prises. Plusieurs inondations y ont déjà eu lieu au cours des années antérieures, la plus significative en 2009 où des maisons ont été inondées pendant presque 60 jours d'affilée. En réponse, une digue de protection (figure 13) a été construite, longue de 1600 mètres de longueur mais celle-ci n'a toutefois pas été très efficace car de nouvelles inondations se sont produites en 2012, 2016 et 2019. Des fortes crues ont submergé l'ouvrage. 


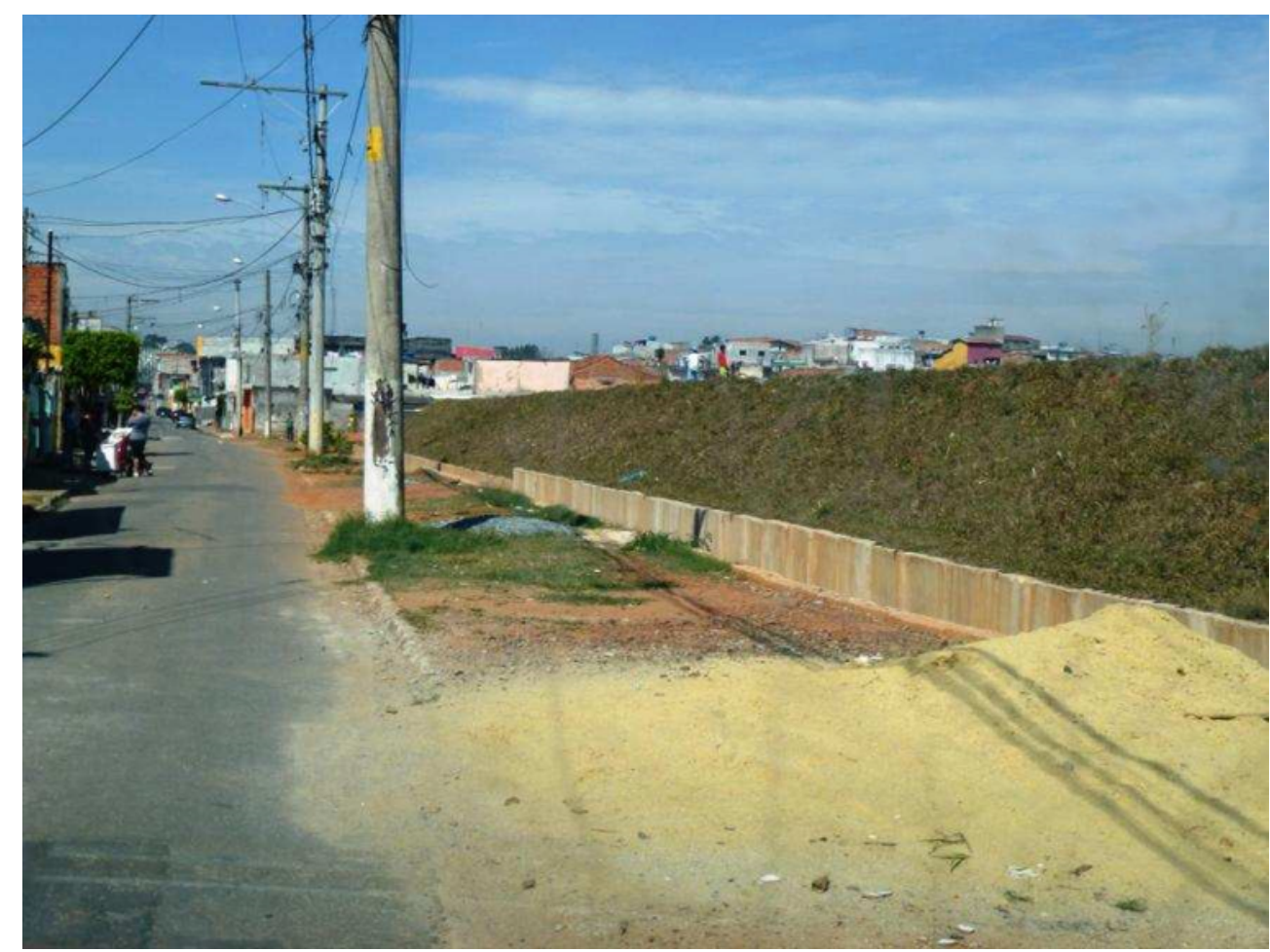

Source : Hervé Théry

La croissance horizontale urbaine de copropriétés de moyen et haut standing et d'habitations de la classe populaire génère de forts impacts environnementaux, la qualité des eaux superficielles est influencée par l'existence et la qualité de l'assainissement. L'absence ou l'inefficacité de la collecte et du traitement entraînent un apport significatif d'eaux usées domestiques dans le Tietê. D'après le Compte rendu sur la qualité des eaux superficielles de l'agence de contrôle environnemental de l'État de São Paulo (CETESB), en 2014 l'unité de gestion des ressources hydriques de la région Alto Tietê présentait $84 \%$ de réseau de collecte d'égouts mais seulement $50 \%$ de traitement (CETESB, 2014).

La croissance désordonnée et socialement inégale provoque donc une dégradation socio-environnementale qui augmente les risques de désastres environnementaux, en particulier dans les zones urbanisées où les conditions sont précaires et la population plus vulnérable. Jatobá S. (2011) pense que si ces régions présentent des risques élevés, elles sont aussi celles où les chances d'améliorer la situation sont les plus grandes, pourvu que soit renforcée la capacité de réponse des individus et des groupes sociaux concernés. Nous reviendrons sur ce point avec les actions des agents des processus de transformation.

\section{Production horticole}

La production horticole et l'élevage de petits animaux sont un autre type d'activité menée dans l'APA-VRT. La première a besoin de grandes superficies de terres proches du lit de la rivière et d'eau pour irriguer ses parcelles (figures 14 et 15). 
Figure 14 Production maraîchère dans l'APA-VRT

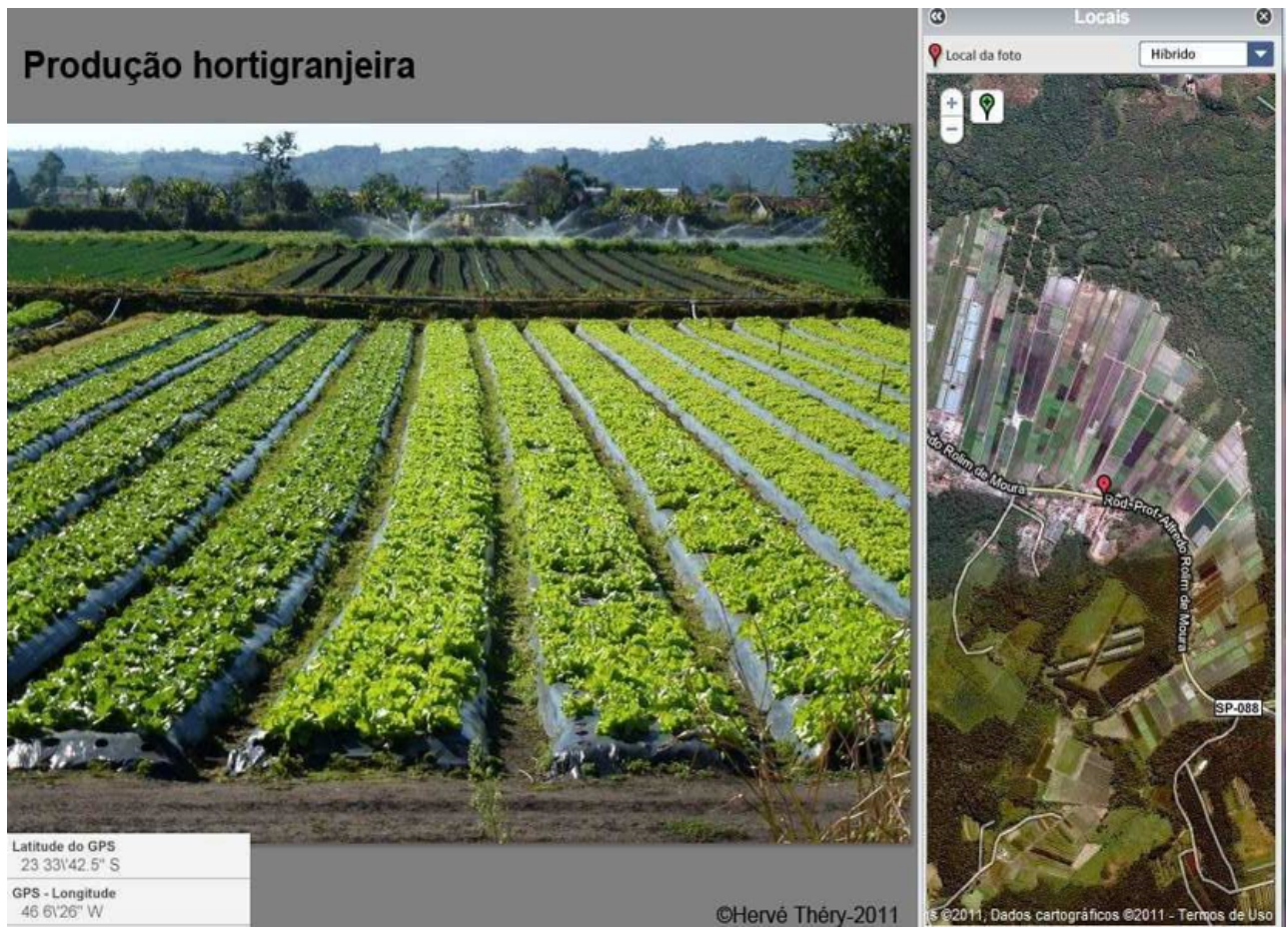

46 Dans la zone de protection environnementale, la compétition pour être le plus près de la rivière a donné lieu à la formation de parcelles longues et étroites - comme le montre clairement la figure 15.

Figure 15 Horticulture au bord du Tietê

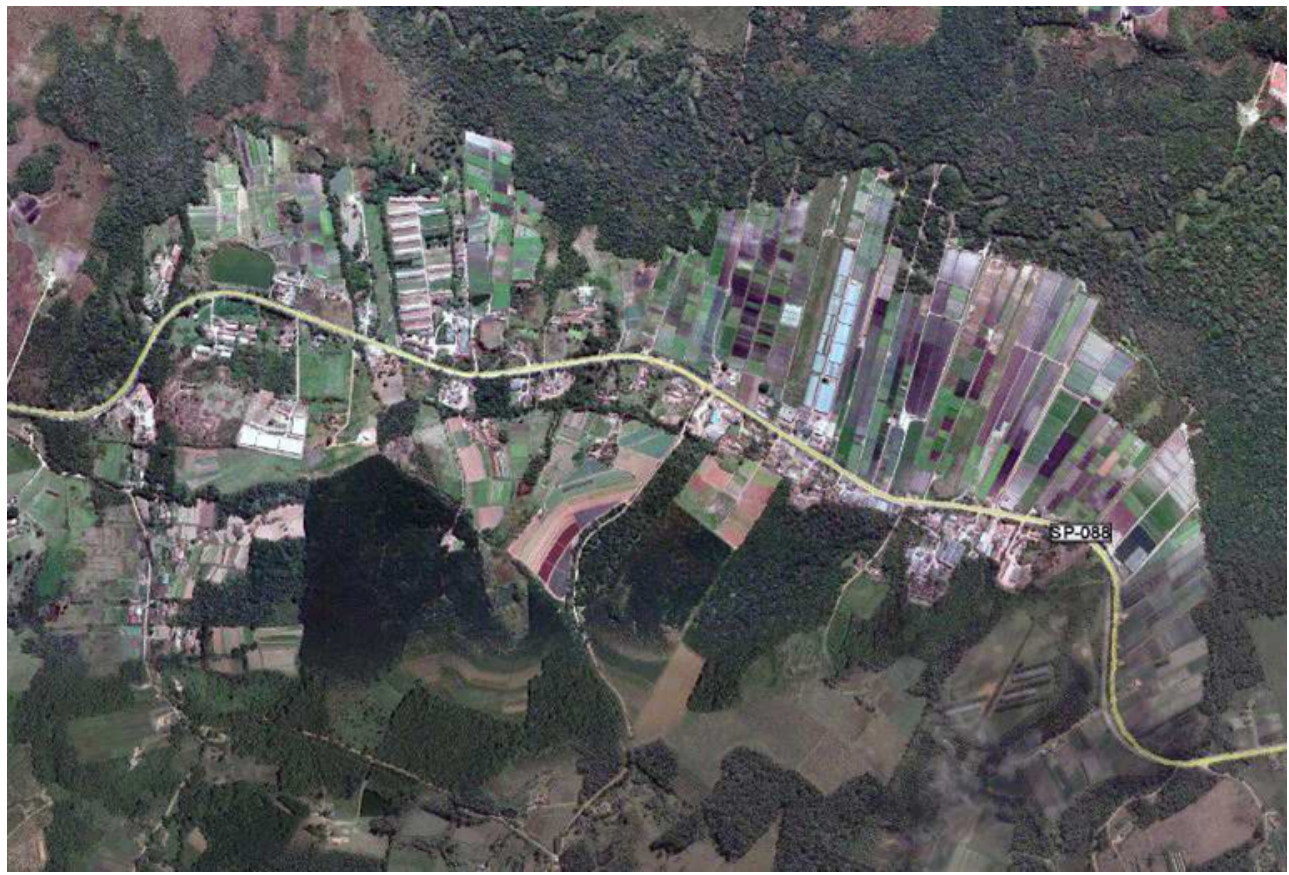

Source : Hervé Théry

47 Qualifiée d'activité potentiellement polluante à cause des résidus d'engrais chimiques utilisés dans les cultures, elle est néanmoins économiquement importante pour la 
région. Des améliorations de cette situation sont possibles, car ce sont dans les régions métropolitaines que des circuits courts peuvent se mettre en place du fait de la proximité d'un vaste marché consommateur comprenant des acheteurs disposés à payer un peu plus cher pour des fruits et légumes orgânicos ${ }^{10}$.

La gestion raisonnée du rapport entre offre et demande en eau pourrait, avec la participation de techniciens, de chercheurs, de la société civile et de producteurs ruraux, contribuer notamment à des projets où tout le monde est gagnant, à la récupération de zones dégradées, à la réduction des conflits par l'approvisionnement en eau et à l'augmentation de la production.

49 À titre d'exemples on peut citer, dans ce domaine, les systèmes de production durables indiqués dans le plan sectoriel brésilien d'agriculture à faible teneur en carbone, ou plan $A B C$. Ou encore le projet producteur d'eau dans le bassin hydrographique de Ribeirão Pipiripau (District Fédéral), un exemple réussi de production et de conservation de l'eau et du sol (Lima J. et Ramos A., 2018). Ce projet s'est fondé sur l'utilisation d'un instrument économique régulé par les forces de marché pour mettre en place un réseau régional de consommateurs intéressés par des produits de l'agriculture durable et de producteurs ruraux désireux de les fournir.

\section{L'industrie dans l'APA-VRT}

Les terrains plats et la disponibilité en eau sont des facteurs qui favorisent l'activité industrielle dans l'APA-VRT, mais sa présence augmente évidemment les risques d'impacts socio-environnementaux négatifs.

Les figures 13 et 14 montrent le cas d'une industrie sidérurgique située dans la plaine. Le secteur présente des risques liés à l'utilisation des ressources naturelles et des risques pour le territoire et les populations environnantes.

Figure 16 Installations industrielles dans l'APA-VRT
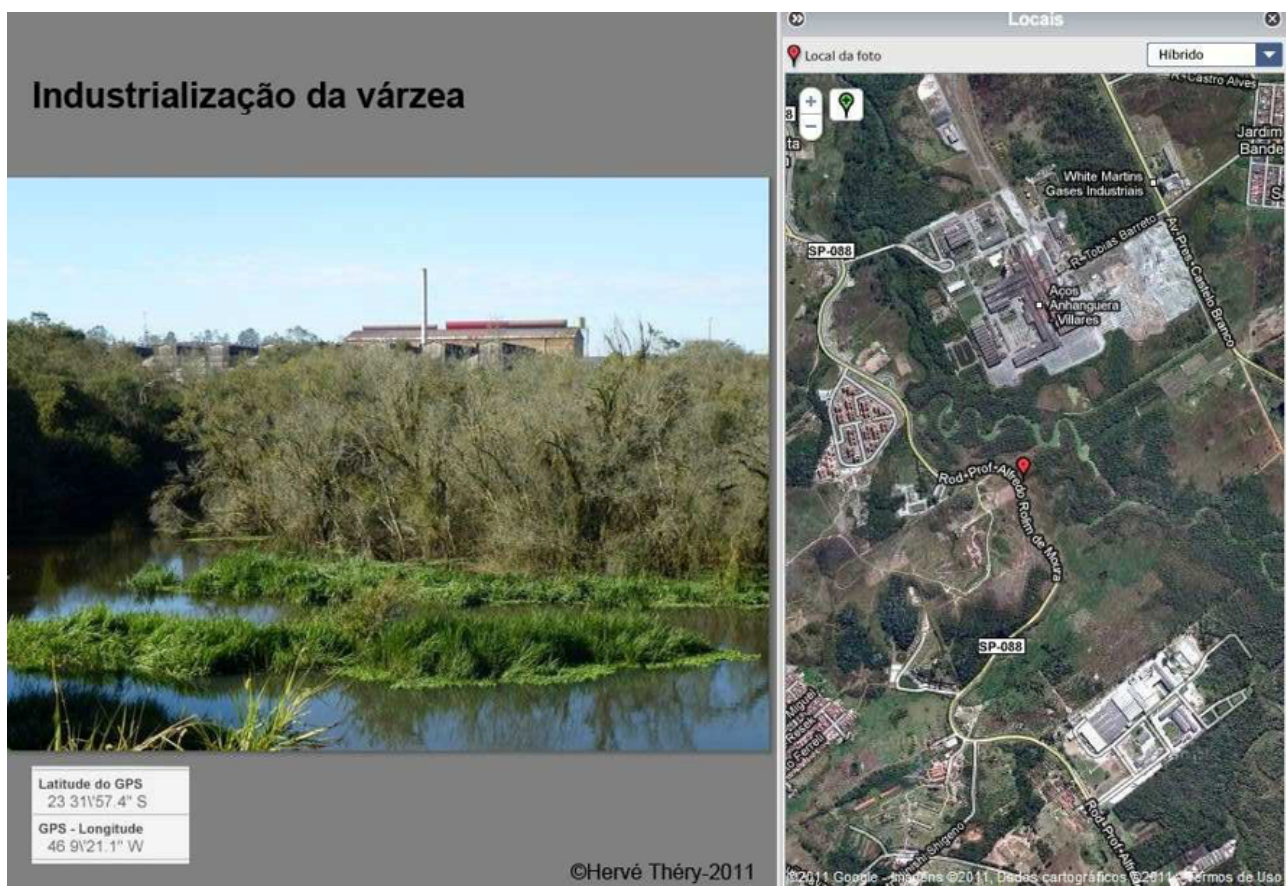
52 La vue détaillée de la figure 17 montre que certaines de ces installations industrielles sont de grande taille, et sont situées très près du Tietê (méandres visibles au bas de la figure).

Figure 17 Industrie sidérurgique située dans l'APA-VRT

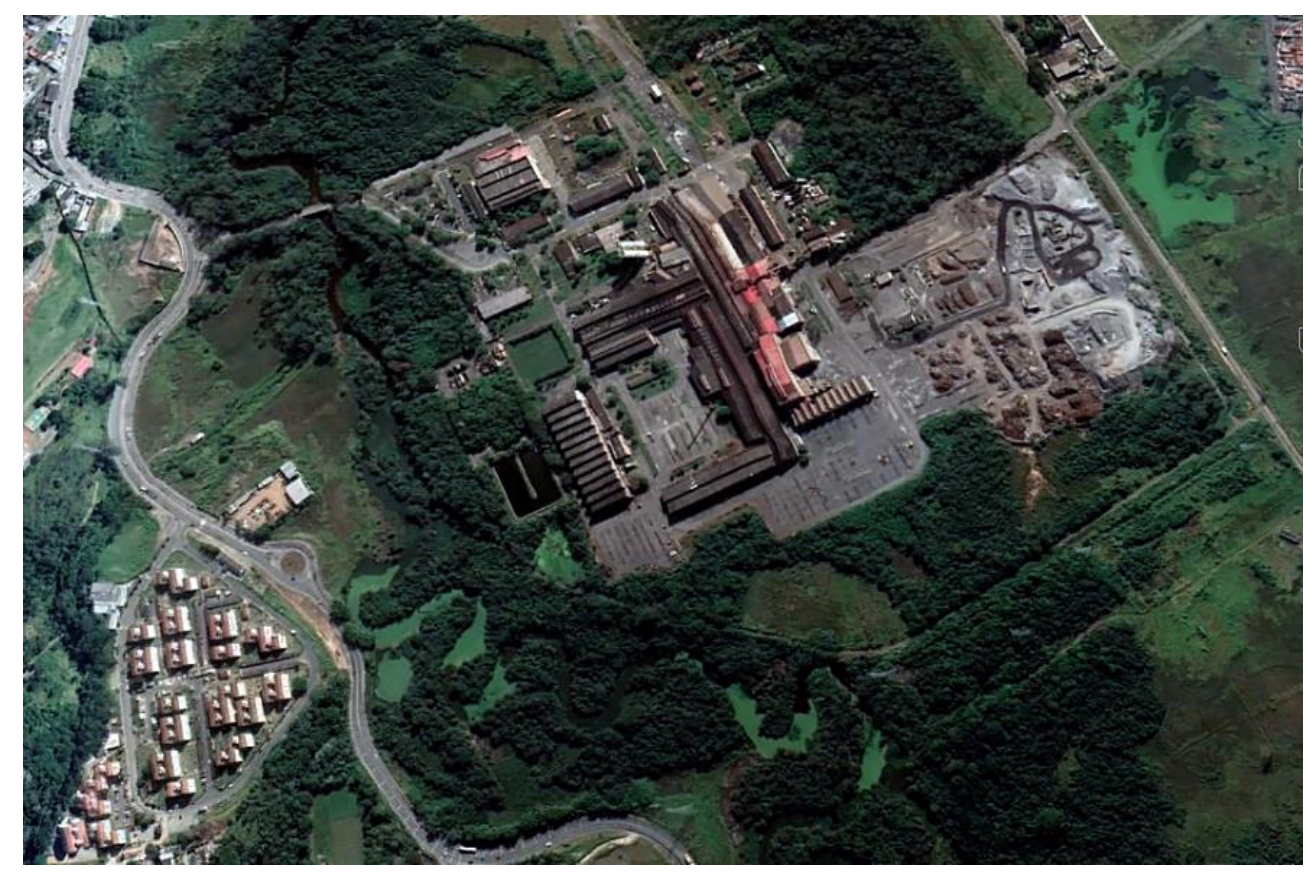

Source : Hervé Théry

Or les complexes sidérurgiques constituent des activités économiques extrêmement polluantes (Milanez B. et M. Porto 2008) et de fait le compte rendu sur la qualité des eaux superficielles de la CETESB pour 2014, a indiqué pour le point TIET02050, situé sur le Tietê (Tietê-Biritiba), des résultats non conformes aux normes de qualité en matière de manganèse, zinc, cadmium, aluminium et fer dissous (CETESB, 2014).

Selon les opposants à cette présence industrielle dans les várzeas, même si les impacts des usines sidérurgiques installées dans la zone de protection environnementale ne sont pas suffisants pour demander leur fermeture ou leur retrait, des actions immédiates devraient cependant être entreprises pour les atténuer. Des exemples de mesures à prendre dans l'APA-VRT sont présentes dans les plans sectoriels brésiliens d'atténuation et d'adaptation aux changements climatiques, comme la production industrielle à partir de sources alternatives et renouvelables, l'adoption de pratiques de recyclage et de remplacement de matériaux, de technologies à teneur en carbone moins intensive, de fours "flex ${ }^{11}$ " pour l'utilisation de charbon de bois produit de manière durable, le contrôle des émissions de gaz, la surveillance et le contrôle des éléments d'échappement. La création d'un label d'efficacité pour le secteur pourrait être une alternative pour ces zones de la région métropolitaine de São Paulo, de façon à chercher la solution des problèmes locaux (ici la pollution par la sidérurgie) par des mesures concrètes inspirées de politiques conçues à plus petite échelle globale : comme souvent il serait bon de penser globalement pour agir localement. 


\section{Agents et processus de transformation de l'APA-VRT} Fondation Forestière de l'état de São Paulo, l'institution qui gère l'unité de conservation et sa présidence, les mairies qui administrent les douze communes, des institutions privées comme le Centre des industries de l'état de São Paulo (CIESP) et des représentations de la société organisée ${ }^{12}$.

Les divergences existent même pour ce qui est de la protection de l'environnement : la zone est simultanément zone de protection environnementale (APA) et zone de préservation permanente (APP), mais chacune a des normes de gestion distinctes et leurs visions tendent parfois à diverger bien que toutes deux aient pour priorité la préservation des várzeas.

57 La divergence des intérêts est plus forte encore sur le plan social. Davies M. (2006) observe que les populations aux faibles revenus n'ont à leur disposition que des lieux peu accessibles et qui sont, généralement, censés être sous protection environnementale. La figure 18 synthétise les vecteurs de pression sur l'APA-VRT : les vecteurs démographiques sont liés à la densité, les vecteurs urbains opposent les zones d'urbanisation déjà consolidée (en rose pâle) de celles où elle avance encore (en rouge) ou appelées à l'être prochainement (lotissements encore non totalement occupés, en orange). Et les pressions sont très différentes si l'on prend en compte les contrastes socio-économiques entre zones peuplées principalement par des populations de classe moyenne (en mauve) de celles qui sont marquées par la pauvreté rurale (en vert) ou urbaine (en orange).

$\mathrm{Du}$ point de vue aussi bien physique que social, les occupations dans des zones vulnérables et à risque résultent du manque de contrôle des pouvoirs publics en termes d'utilisation du sol, mais aussi de la planification immobilière. Du fait de l'instrument de régularisation foncière et de la désignation de Zones spéciales d'intérêt social (ZEIS, sigle en portugais), le déplacement de populations et leur réinstallation ailleurs est rare dans la région métropolitaine de São Paulo (et au Brésil en général), bien que cela soit arrivé en 2009, pour 222 familles qui occupaient l'espace nécessaire pour la construction de la digue de protection du Jardim Romano. 
Figure 18 Vecteurs de pression sur l'APA-VRT

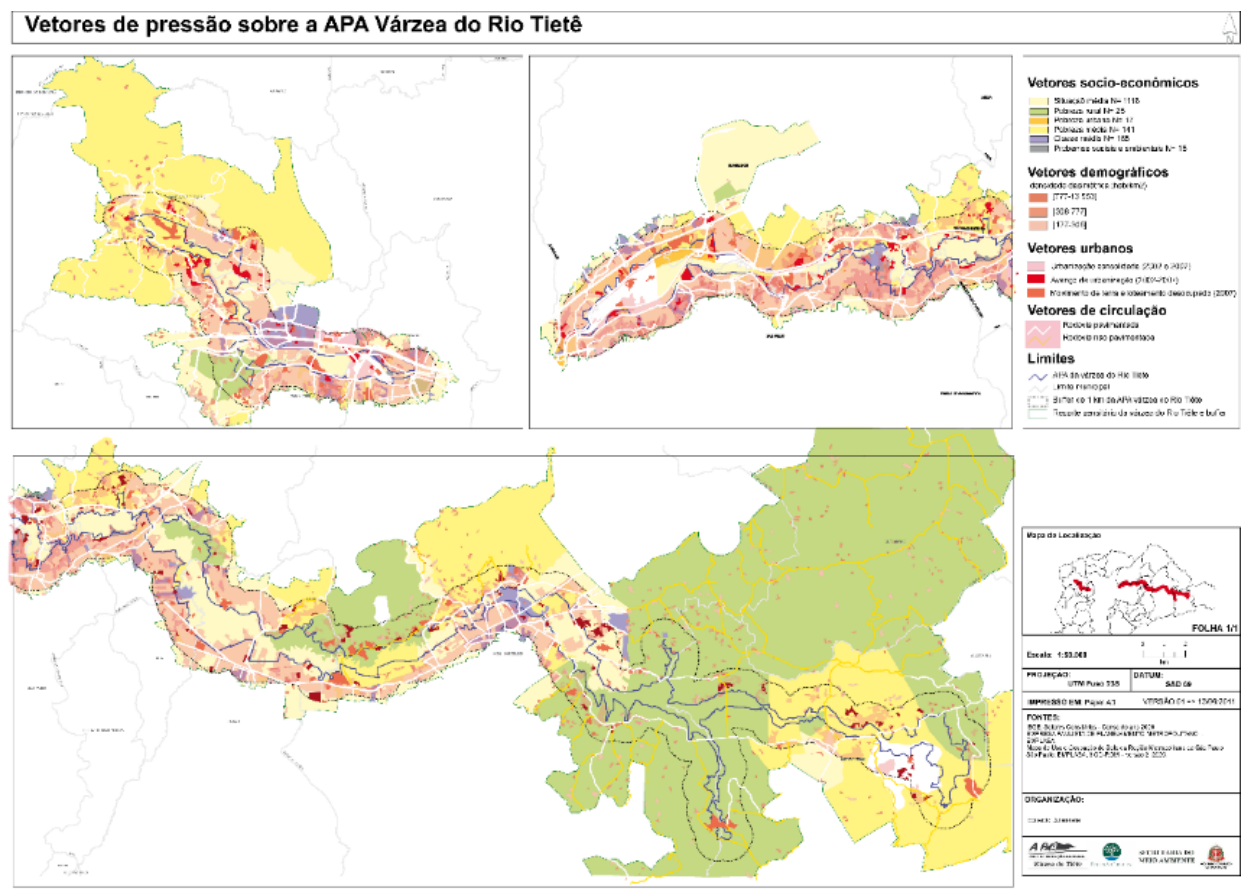

Figure 18 légende traduite

\section{Vecteurs socio-économiques}

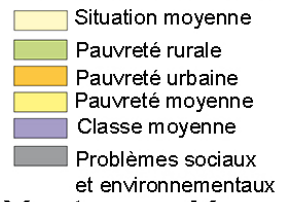

\section{Vecteurs démographiques}

Densité dasimétrique (hab/km2)

$777-13553$

$\square$ 306-776

$\square$ 177-305

\section{Vecteurs urbains}

Urbanisation consolidée (2002 et 2007)
Avancée de l'urbanisation (2007/2007)
Terrassements et lotissements vides (207)

\section{Vecteurs de ciculation}

Route asphaltée

Route non asphaltée

\section{Limites}

\footnotetext{
APA varzea du Tietê Limite de commune

:........... Buffer d'1 km /APA

Limite de secteur censitaire
}

Des actions menées par les agents publics et par la population seraient certainement à mener pour répondre à la fréquence des inondations dont il est prévisible qu'elle augmente : les études sur les changements climatiques et leurs effets dans la région métropolitaine de São Paulo prévoient 1,5 inondations tous les deux ans (Nobre C. et al., 2010). Une situation qui exige une planification et une exécution à court, moyen et long 
terme. Plusieurs quartiers de la zone Est de São Paulo, comme Jardim Romano, Jardim Pantanal et Vila Itaim, vivent depuis des années au rythme des crues de durée diverse. En plus de l'eau qui envahit les maisons, la population est confrontée aux maladies transmises par l'eau, à la pollution hydrique et à d'autres difficultés. En 2012, 2016 et 2019 de nouvelles intempéries ont atteint la région.

Si de tels événements étaient vraiment perçus comme prioritaires, il serait souhaitable que chaque membre du Conseil de gestion défende non pas son seul point de vue mais l'intérêt commun, l'utilisation rationnelle et intégrée des plaines inondables pour des activités résidentielles, industrielles et activités agricoles. Leurs prises de position tendent parfois à s'éloigner de l'objectif premier de la création de l'APA-VRT, qui était la protection des plaines inondables du Tietê...

Prenons l'exemple de la représentation des populations vivant à Jardim Romano : leurs actions au sein du Conseil de l'APA a toujours été de demander la régularisation foncière du quartier, le maintien de la population sur place et la construction de digues, et ce, malgré la nécessité de retirer et de reloger ailleurs certaines familles. À aucun moment les informations scientifiques sur les changements climatiques n'ont été prises en compte pour penser à réduire le nombre d'habitations ou à reloger les familles trop proches du cours d'eau. De la même manière, le Centre des industries de São Paulo (CIESP) défendait l'utilisation de la plaine inondable pour les activités industrielles et le maintien des installations existantes. Certaines entités municipales se battaient pour garantir des projets immobiliers dans la plaine, dans des zones centrales de leur villes, tandis que d'autres se souciaient de la qualité de l'eau de la rivière mais sans faire le lien avec les utilisations des sources ou des rives de la rivière.

\section{Politiques et projets dans la zone de protection environnementale de la zone inondable du Tietê}

Massardier G. (2003) définit comme politiques publiques celles qui proviennent d'une construction collective complexe, dirigée par des acteurs sociaux (ou groupes d'acteurs), des organisations publiques et des organisations internationales, et Vianna J. (1996) affirme qu'elles comprennent une action gouvernementale planifiée qui vise, par divers processus, à atteindre un objectif. L'action publique doit reposer sur cinq processus simultanés et parfois contradictoires :

1) la division sociale croissante du travail ;

2) une plus grande ouverture des décideurs à leurs multiples « dogmes »;

3) la transversalité de l'action publique (politiques dites intégrées);

4) une corrélation à sa territorialisation ;

5) l'élaboration de politiques publiques dans les arènes et les réseaux (Massardier G., $2011: 85)$.

Nous avons identifié les cinq processus, bien qu'à des degrés et des intensités variables, dans la construction du diagnostic pour le plan de gestion de l'APA-VRT.

Le scénario est encore plus complexe quand on analyse les différents projets et politiques sur le territoire de l'APA-VRT. D'après Pessoa D. (2006), le Tietê et ses plaines inondables sont depuis longtemps l'objet de l'attention publique et concernées par des plans et des projets, de rectification, construction d'infrastructures (routes et 
Hidroanel ${ }^{13}$ ), dépollution, dragage, création de parcs, plans de drainage et de gestion du bassin hydrographique.

Formulés et exécutés par divers organismes publics, les plans, programmes et projets des politiques publiques présentent différents degrés d'intégration ou de sectorisation. En plus de l'APA-VRT qui vise la récupération et la protection des plaines d'inondation de la région, il existe notamment le programme Parc des plaines inondables du Tietê (PVT), du département des Eaux et de l'Énergie électrique (DAEE), pour créer des parcs linéaires ; le Plan de bassin hydrographique d'Alto Tietê ; le Projet Tietê de dépollution de la rivière, par la Compagnie d'assainissement de l'État de São Paulo (SABESP); le projet Hidroanel pour le transport de charges et de résidus solides sur les cours d'eau, du Département des voies d'eau du Secrétariat d'état à la logistique et aux transports ; et le Plan directeur de macro-drainage du Bassin de l'Alto Tietê, mené par le DAEE, pour les infrastructures destinées à contrôler les inondations et le drainage.

71 Plus spécifiquement, le programme Parc des plaines inondables du Tietê (PVT) ${ }^{14}$ a remplacé le projet antérieur de Burle Marx, daté de 1974, pour la protection et la création de zones de loisirs dans les plaines inondables (Fundação Florestal, 2013). Le programme répète les objectifs de l'APA-VRT, il vise la préservation des plaines inondables du Tietê et l'atténuation des crues. Il en est différent au sens où l'APA-VRT établit un zonage et un plan de gestion pour orienter l'utilisation du sol et le PVT porte sur la création d'un parc linéaire et le déplacement d'une partie de la population des zones vulnérables de la plaine d'inondation (DAEE, 2019).

Le programme présente une série d'actions dont le dragage de la rivière, des travaux de drainage, la construction de parcs urbains, des pistes cyclables, un canal périphérique, des polders, la recomposition de forêts ciliaires, le retrait et le relogement de familles et de commerces. Il est divisé en trois étapes sur une longueur de $75 \mathrm{~km}$ et de $107 \mathrm{~km}^{2}$ sur les territoires de São Paulo, Guarulhos, Itaquaquecetuba, Poá, Suzano, Mogi das Cruzes et Biritiba Mirim (Sato D., 2018). Lancé en 2009 et d'une durée initialement prévue de 11 ans, ses actions et ses comptes rendus se limitent jusqu'à présent à l'étape 1, dans les communes de São Paulo et Guarulhos.

73 Comme on le voit, il existe depuis le début un effort d'articulation entre l'APA-VRT et le PVT, notamment symbolisé par la participation de représentants du Conseil de gestion de l'APA au PVT et du DAEE au Conseil de l'APA. L'initiative est d'autant plus importante que les actions du PVT s'insèrent majoritairement dans la zone Est de l'APA-VRT, la zone la plus préservée et où les possibilités d'actions sont les plus élevées, mais qui, simultanément, subit des pressions d'expansion urbaine (DAEE, 2019). Toutefois, la participation n'implique pas nécessairement des actions alignées (Scatena G., 2015 ; Sato D., 2018).

74 Les figures 19 et 20 représentent les actions menées par le Département des eaux et de l'énergie électrique pour la Banque interaméricaine de développement (BID) (DAEE, 2019). Le secteur Est compte le plus grand nombre d'actions dans les várzeas de la région métropolitaine de São Paulo, qui jouent le rôle de réservoirs pendant les crues et atténuent ainsi les inondations (Rodrigues C., 2015). 
Figure 19 Actions du programme Parc des plaines inondables du Tietê (PVT) partie ouest

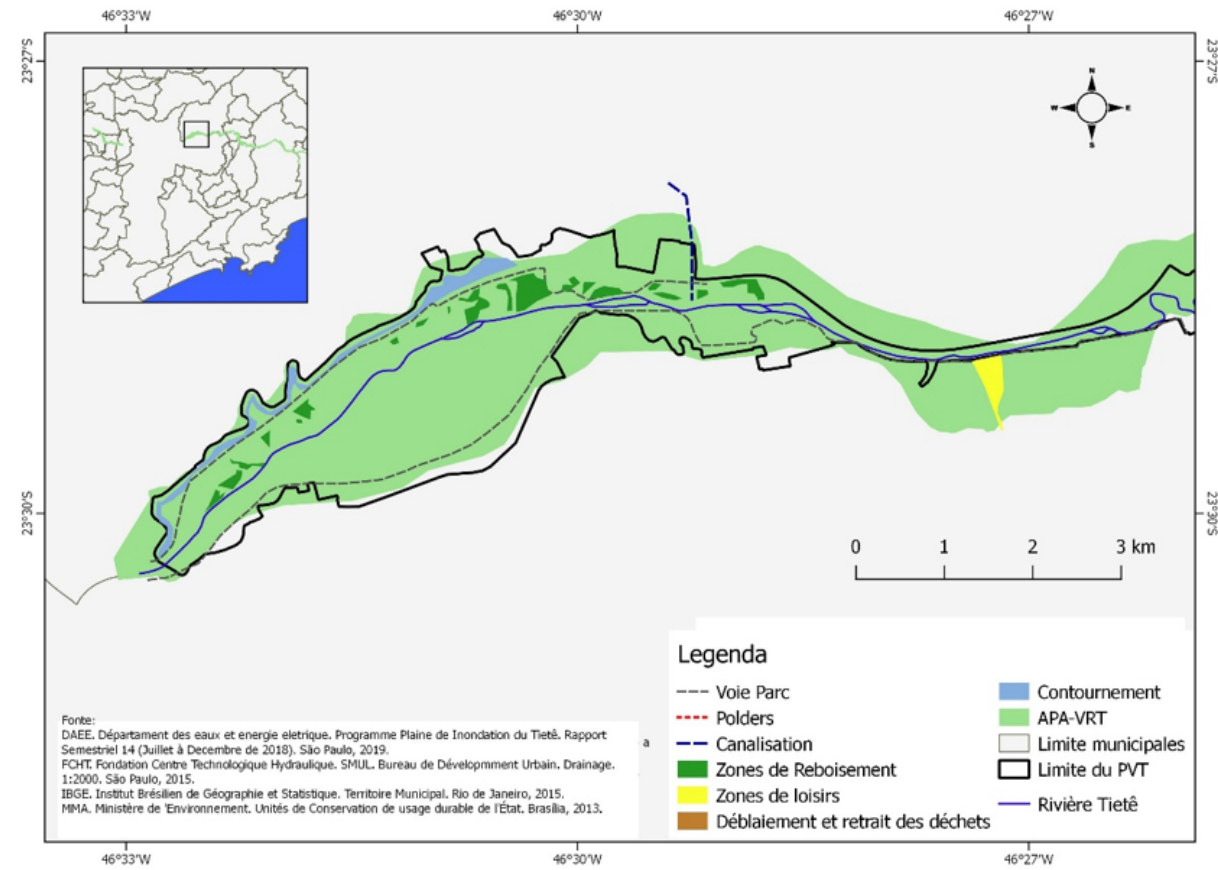

Figure 20 Actions du programme Parc des plaines inondables du Tietê (PVT) partie est

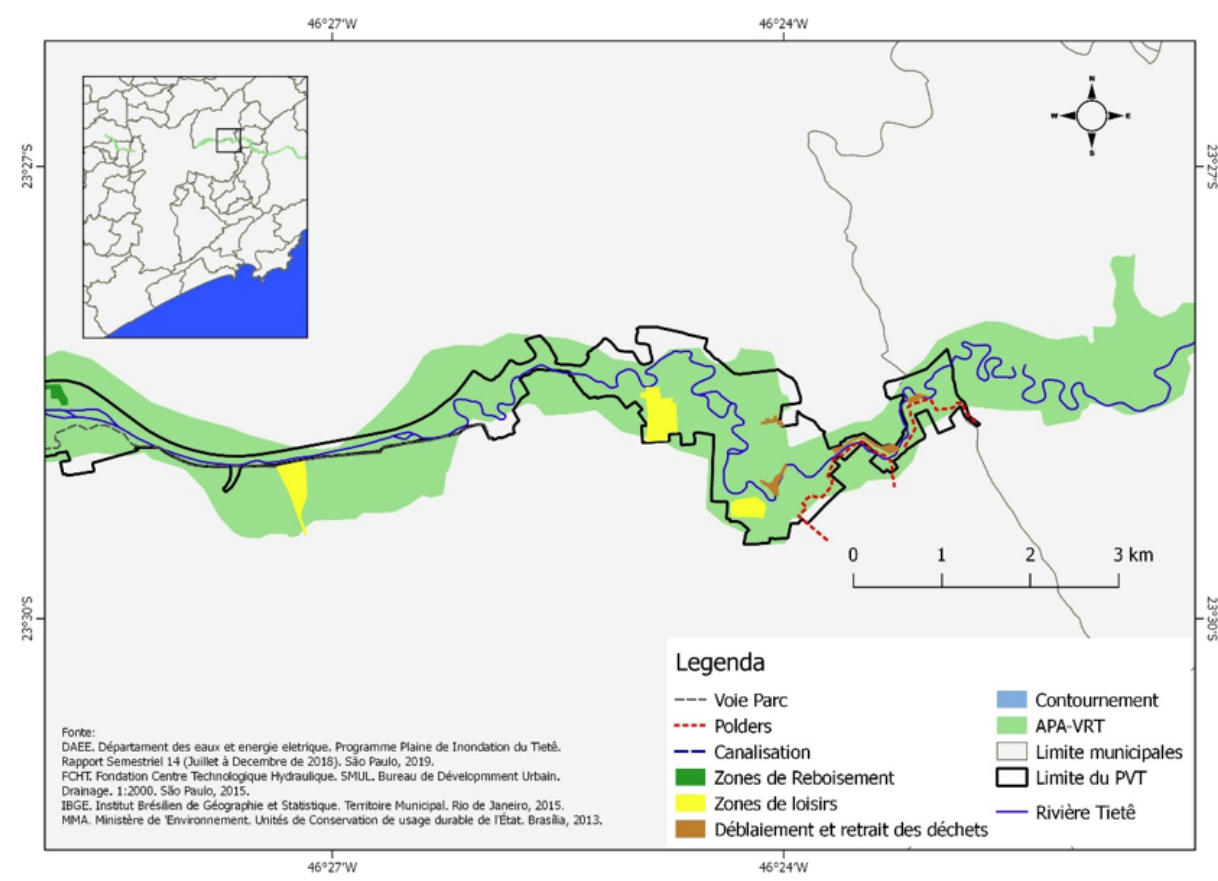

$N B$ : dans la limite de la zone de protection environnementale des plaines inondables du Tietê $(A P A-V R T)$

Le relogement de familles qui habitaient dans les zones à risque, ainsi que le dragage du Tietê dans la partie concernée par l'Étape 1 du PVT, visent à augmenter le volume d'eau qui peut être retenu dans les várzeas. Au total, 675 familles ont été relogées entre 2014 et 2017 avec la collaboration du Secrétariat d'État au logement de São Paulo. S'y 
ajoutent 63 familles dans un autre grand ensemble avec l'aide de la Compagnie de développement urbain.

Les zones de pression urbaine et occupées dans les limites du PVT sont les plus vulnérables aux inondations, aussi bien dans le Plan de gestion de l'APA-VRT que dans les études pour le relogement des 738 familles qui vivent au sein de la zone de protection environnementale des plaines d'inondation du Tietê et du Parc des plaines d'inondation du Tietê (Fundação Florestal, 2013; DAEE, 2019). Toutefois, certains travaux du PVT modifient les attributs naturels des várzeas et ont contribué à la perte de la fonction environnementale de rétention des eaux (Rodrigues C., 2015).

\section{Conclusion}

La zone de protection environnementale des plaines d'inondation du Tietê (APA-VRT) constitue donc un exemple complexe de cas où la vulnérabilité se fonde sur la relation entre les changements environnementaux, les conditions sociales et les actions publiques.

Reprenant les observations de Jatobá S. (2011) on peut conclure que l'APA-VRT présente les caractéristiques suivantes concernant les trois principaux facteurs présents dans les définitions sur la vulnérabilité :

I. Une exposition élevée de la population au risque, en particulier pour les logements des personnes à faible revenu, et aux impacts socio-environnementaux potentiels. La dégradation environnementale est aggravée par les formes désordonnées et inégales de la croissance urbaine ;

II. Les ressources à la disposition de la population ne sont pas adaptées pour faire face à ces risques, notamment l'accès aux biens et aux services marchands, les possibilités d'emploi, d'éducation, d'accès aux services de santé, d'assainissement et de conditions de logement ;

III. Une capacité insuffisante de réponse aux risques causée par l'inefficacité de la mise en œuvre des législations qui y sont liées, d'une mauvaise gestion des conflits, de l'action inefficace du Conseil de gestion de l'APA-VRT et de l'absence de prise en compte des orientations sur l'occupation et l'utilisation des sols dans les plaines inondables.

Même s'il s'agit d'une zone protégée, le processus d'occupation urbaine des várzeas, qu'il soit dû au besoin de logement, à l'occupation agricole ou industrielle, s'est fait sans respecter la loi et sans tenir compte des conditions intrinsèques. Les institutions responsables de la gestion de cette aire protégée n'ont pas réussi à contrôler l'utilisation du territoire. Les actions publiques y ont même contribué, en stimulant différents projets dans le fond de la vallée, négligeant la pression immobilière et industrielle et en étant très lentes par rapport à la dynamique locale, ne serait-ce que par le long délai entre la création de l'APA, son zonage, et la définition de son plan de igestion.

81 Cet échec peut être expliqué par le degré élevé de conflictualité entre ce que doit être la protection et la pression immobilière au sein de l'APA-VRT. La situation montre l'inefficacité de gestion de la croissance démographique et de l'aménagement du territoire de la région métropolitaine de São Paulo, la plus grande région métropolitaine du Brésil. 


\section{BIBLIOGRAPHIE}

Companhia Ambiental do Estado do São Paulo (CETESB), Qualidade das águas superficiais no Estado de São Paulo, 2014

Davies, Mike, Planeta Favela, São Paulo, Boitempo, 2006

Departamento de Águas e Energia Elétrica (DAEE), Relatório semestral de acompanhamento da execução do programa várzeas do Tietê - PVT, 14ํㅡㄴ relatório semestral de acompanhamento, São Paulo, SIMA, 2019

Egler, Claudio A. G., « Risco ambiental como critério de gestão do território: uma aplicação à zona costeira brasileira », Revista Território, Rio de Janeiro, 1(1), 1996, p. 31-41

Fortunato, Ivan, Fortunato Neto, José, « Risco ambiental a luz dos princípios de precaução e da prevenção ", in Guimarães, Solange T, de L., Carpi JR, Salvador, Godoy, Manuel B. R. B., Tavares, Antônio C. (orgs), Gestão de áreas de riscos e desastres ambientais, Rio Claro, IGCE/UNESP/RIO CLARO, 2012, p. 12-31

Fundação Florestal, Plano de Manejo da Área de Proteção Ambiental das Várzeas do Rio Tietê, vol. 1, São Paulo, SMA, 2013

Gouveia Moroz-Caccia, Isabel Cristina. « A cidade de São Paulo e seus rios: uma história repleta de paradoxos ", Confins 27, 2016, mis en ligne le 16 juillet 2016, consulté le 25 août 2019. URL : http://journals.openedition.org/confins/10884 ; DOI : 10.4000/confins.10884, consulté le 19 janvier 2020

Intergovernmental Panel on Climate Change. IPCC. Climate Change 2014: Impacts, Adaptation and Vulnerability, Part B Regional Aspects, IPCC, 2014

Jatobá, Sérgio U.S., « Urbanização, meio ambiente e vulnerabilidade social », Boletim regional, urbano e ambiental, 2011, p.141-148, http://repositorio.ipea.gov.br/handle/11058/5567, consulté le 25 juin 2019

Lara, Walace, «Justiça de SP anula novo zoneamento de área de proteção ambiental do Tietê », G1, 16 juin 2018, https://g1.globo.com/sp/sao-paulo/noticia/justica-de-sp-anula-novozoneamento-de-area-de-protecao-ambiental-do-tiete.ghtml, consulté le 20 juin 2019

Lima, Jorge E.F.W. \& Ramos, Alba E., A experiência do Projeto Produtor de Água na bacia hidrográfica do Ribeirão Pipiripau, Brasília, ADASA, v. 1, 2018

Lombardo, M.A., Ilha de calor nas metrópoles - o exemplo de São Paulo, São Paulo, Hucitec, 1985

Massardier, Gilles, « Cognição, políticas e ações públicas: entre coerência, fragmentação e aprendizados », In: Bonnal, Philippe e Leite, Sérgio Pereira (org.), Análise comparada de políticas públicas: uma agenda em transformação, Rio de Janeiro, Mauad, 2011

Massardier, Gilles, Politiques et actions publiques, Paris, Armand Colin, 2003.

Milanez, Bruno, Porto, Marcelo F.S., « A ferro e fogo: impactos da siderurgia para o ambiente e a sociedade após a reestruturação dos anos 1990 » In : IV Encontro Nacional da Anppas, Brasilia, 4-6 junho 2008, http://anppas.org.br/encontro4/cd/ARQUIVOS/GT6-61-8-20080509163054.pdf, consulté le 27 juillet 2019

Ministério Público do Estado de São Paulo, Processo 1023452-67.2017.8.26.0053, São Paulo, 2017 
Nobre, Carlos, Young, Andrea, Saldiva, Paulo et al., Vulnerabilidades das Megacidades Brasileiras às Mudanças Climáticas : Região Metropolitana de São Paulo. Centro de Ciência do Sistema Terrestre do Instituto Nacional de Pesquisas Espaciais (INPE), Núcleo de Estudos de População da Universidade de Campinas (UNICAMP), Faculdade de Medicina da Universidade de São Paulo (USP), Instituto de Pesquisas Tecnológicas de São Paulo (IPT), Universidade Estadual Paulista (UNESP - Rio Claro), Juin 2010

Pessoa, Denise Falcão, Utopies et villes : propositions, São Paulo, Annablume, 2006

Rodrigues, Cleide. « Atributos ambientais no ordenamento territorial urbano : o exemplo das planícies fluviais na metrópole de São Paulo », GEOUSP Espaço e Tempo, vol. 19, n. 2, 2015, p. 324-347, http://www.revistas.usp.br/geousp/article/view/102805, consulté le 20 juin 2019

Santos, Rosely Ferreira dos (Org.), Vulnerabilidade ambiental: desastres naturais ou fenômenos induzidos?, Brasília, MMA, 2007

Sato, Danilo Pereira, Territórios e conflitos na Área de Proteção Ambiental da várzea do rio Tietê, mémoire de master, Geografia Humana, USP, 2018, http://www.teses.usp.br/teses/disponiveis/ 8/8136/tde-21112018-110051/pt-br.php, consulté le 15 juin 2019

Scatena, Gil Kuchembuck, Áreas de proteção ambiental e os desafios da gestão territorial para a sustentabilidade : o caso da APA da Várzea do Rio Tietê, mémoire de master, Planejamento e gestão do território, UFABC, 2015, https://sites.google.com/site/pospgt/publicacoes/gil-kuchembuckscatena, consulté le 25 juillet 2019

Théry, Hervé, « Le Tietê, le fleuve de São Paulo », Braises, 2016, https://braises.hypotheses.org/ 1061, consulté le 17 janvier 2020

Théry, Hervé, « Travail de terrain dans la haute vallée du Tietê », Braises, 2011, https:// braises.hypotheses.org/129, consulté le 17 janvier 2020

Tyrväinen, Liisa et al. « Benefits and uses of urban forests and trees », Urban forests and trees, Springer, 2005, p. 81-114

Viana, João Paulo et al. « Avaliação do estado de conservação da biodiversidade brasileira: desigualdades entre regiões e unidades da Federação ». In: Rogério Boueri e Marco Aurélio Costa (eds.), Brasil em desenvolvimento 2013: estado, planejamento e políticas públicas, Brasília, Ipea, 2013, vol. 3, p. 757-792.

\section{NOTES}

1. Il convient de rappeler la thèse classique de Lombardo M. (îlot de chaleur dans la métropole paulistana) qui, en 1984 a dévoilé la genèse des températures les plus chaudes à l'intérieur de la métropole de São Paulo et qui a généralisé ce concept.

2. Salesópolis, Biritiba Mirim, Mogi das Cruzes, Suzano, Poá, Itaquaquecetuba, Guarulhos, São Paulo, Osasco, Carapicuíba, Barueri et Santana do Parnaíba.

3. L'étude de référence a été réalisée pour la Fondation Forestière par une équipe pluridisciplinaire - comprenant les auteurs de l'article - de l'Université de São Paulo-USP (contrat TAG/Petrobras/FUSP numéro 7102.0000344.10.2 entre 2011 et 2012). Pour cet article, des nouvelles études ont été incluses, en particulier les résultats présentés dans un mémoire de $3^{\mathrm{e}}$ cycle en géographie humaine à l'USP et dans une recherche de postdoctorat de deux des auteurs.

4. $N d T$ : large bande de végétation primaire qui protège les sources et les berges. 
5. NdT : Aglomerados subnormais, littéralement agglomérats sous-normaux, appellation donnée par l'Institut brésilien de géographie et statistiques (IBGE) pour désigner les bidonvilles, quand il y a urbanisation en dehors des standards.

6. $N d T$ : Condomínios : espaces résidentiels, la plupart du temps fermés et surveillés.

7. Bien que les sols de certaines d'entre elles soient parfois contaminés à cause de l'utilisation excessive et durable d'engrais chimiques ou du traitement minier antérieur.

8. Empresa paulista de planejamento metropolitano SA, l'organisme de planification de la région métropoliaine de São Paulo

9. Vérifié sur place par les auteurs en se faisant passer pour des acheteurs potentiels : en 2011 les parcelles se vendaient en moyenne pour 250000 Reais (environ 125000 Euros) et la vendeuse indiquait avec fierté qu'aucune des maisons alors construites n'avait coûté moins d'un million de Reais (500 000 Euros).

10. NdT: équivalent en portugais du Brésil de "bio" en français

11. $N d T$ : acceptant plusieurs types de combustibles

12. $N d T$ : leurs équivalents français seraient des ONG et des associations régies par la loi de 1901.

13. NdT: Hidroanel : projet destiné à rendre les cours d'eau de la région métropolitaine de São Paulo navigables.

14. Programme élaboré par Ruy Ohtake, architecte et paysagiste renommé au Brésil.

\section{RÉSUMÉS}

L'article analyse la situation de la zone de protection de l'environnement de la plaine inondable du Tietê (APA-VRT) et des zones de préservation permanente (APP) dans la région métropolitaine de São Paulo. L'accent est mis sur les vulnérabilités, les risques et les changements liés à l'utilisation des terres, ainsi que sur le rôle des acteurs dans le processus de transformation et leurs relations avec les actions publiques visant la préservation de l'environnement et la défense du bien commun. Le texte contient 20 illustrations élaborées par la cartographie de données collectées à diverses sources statistiques, de l'analyse d'images et de travaux de terrain menées dans l'APA-VRT.

O artigo analisa a situação da Área de Proteção Ambiental da várzea do rio Tietê (APA-VRT) e das Áreas de Preservação Permanente (APP) no contexto da região metropolitana de São Paulo, ressaltando as vulnerabilidades e riscos, as mudanças de uso do solo, seguidas pela apreciação dos atores, suas ações no processo de transformação e as suas relações com as ações públicas voltadas para a conservação ambiental e pela defesa do bem comum. O texto contém 20 ilustrações desenvolvidas pelo mapeamento de dados coletados de várias fontes estatísticas, análise de imagens e trabalho de campo realizado na APA-VRT.

The article analyses the situation of the Tietê River floodplain Environmental Protection Area (APA-VRT) and the Permanent Preservation Areas (APP) in the context of the metropolitan region of São Paulo, highlighting the vulnerabilities and risks, changes in land use, followed by appreciation of the stakeholders, their actions in the transformation process and their relations with public actions aimed at environmental conservation and the defense of the common good. The text contains 20 illustrations developed by mapping data collected from various statistical sources, image analysis and field work carried out in the APA-VRT. 


\section{INDEX}

Keywords : Vulnerabilities, risks, conflicts, Tietê River floodplain APA (São Paulo), Brazil.

Palavras-chave : Vulnerabilidades, riscos, conflitos, APA Várzea do rio Tietê (São Paulo), Brasil.

Mots-clés : Vulnérabilités, conflits, zone de protection environnementale de la plaine d'inondation de la rivière Tietê (São Paulo), Brésil

\section{AUTEURS}

\section{NELI APARECIDA DE MELLO-THÉRY}

Neli Aparecida de Mello-Théry est professeur à l'Université de São Paulo, à l'École des Arts, Sciences et Humanités (EACH/USP), coordinatrice du groupe de recherche Politiques publiques, territorialités et société à l'Institut d'Études Avancées de l'USP. Ses thèmes de recherche sont l'Amazonie, la gestion de l'environnement, les dynamiques territoriales, les politiques environnementales, le développement durable, les politiques internationales. Coéditrice de la Revue Franco-Brésilienne de Géographie Confins. (https://journals.openedition.org/ confins)namello@usp.br

\section{HERVÉ THÉRY}

Hervé Théry est directeur de recherche émérite au Centre National de la Recherche Scientifique (CNRS), professeur au programme de pos graduation en général humaine à l'Université de São Paulo (USP) et membre du groupe de recherche Politiques publiques, territorialités et société à l'Institut d'Études Avancées de l'USP. Co-éditeur de la Revue Franco-Brésilienne de Géographie Confins. (https://journals.openedition.org/confins). Thèmes de recherche : Géographie régionale et politique, Géographie du Brésil, Cartographie thématique, Modélisation graphique. Auteur du Blog de recherche Braises (http://braises.hypotheses.org/).hthery@aol.com

\section{DANILO PEREIRA SATO}

Master en Géographie Humaine à l'Université de São Paulo, licence de Gestion de l'environnement à l'École des Arts, Sciences et Humanités (EACH/USP). Doctorant et boursier au projet « Démocratie, Arts et Savoir Pluriels ». Expérience dans les domaines de l'aménagement environnemental, la géographie politique, les politiques territoriales et le patrimoine culturel.Danilo.sato@usp.br

\section{HELOISA DE CAMARGO TOZATO}

Heloisa de Camargo Tozato est chercheuse à l'IPC-IG/PNUD de l'Institut de Recherche Économique Appliquée (IPEA). Membre du groupe de recherche Politiques publiques, territorialités et société à l'Institut d'Études Avancées de l'USP. Ses thèmes de recherche sont les politiques publiques pour atteindre les Objectifs du développement durable, en particulier l'adaptation au changement climatique. Docteur en Sciences de l'USP et Docteur en Géographie de l'Université de Rennes 2 - Haute Bretagne (France). Lauréat du prix de thèses USP 2016 dans la catégorie Sciences de l'environnement (São Paulo, Brésil).htozato@gmail.com 